\title{
Gene Expression Profiling of Muscle Stem Cells Identifies Novel Regulators of Postnatal Myogenesis
}

\section{OPEN ACCESS}

Edited by:

Atsushi Asakura

University of Minnesota, USA

Reviewed by:

Akiyoshi Uezumi,

Fujita Health University, Japan Lucia Latella,

National Research Council of Italy, Italy

${ }^{*}$ Correspondence:

Sonia Alonso-Martin alonsomartin.s@gmail.com;

Frédéric Relaix

frederic.relaix@inserm.fr

${ }^{\dagger}$ Present Address:

Sonia Alonso-Martin,

Tissue Regeneration Laboratory,

Centro Nacional de Investigaciones

Cardiovasculares, Madrid, Spain

Ted Hung-Tse Chang,

International Centre for Genetic

Engineering and Biotechnology,

Cancer Genomics Group, Anzio Road,

Cape Town, South Africa

Specialty section:

This article was submitted to

Stem Cell Research,

a section of the journal

Frontiers in Cell and Developmental

Biology

Received: 29 January 2016 Accepted: 02 June 2016

Published: 21 June 2016

Citation:

Alonso-Martin S, Rochat A

Mademtzoglou D, Morais J, de Reyniès A, Auradé $F$, Chang TH-T and

Zammit PS Relaix F (2016) Gene Expression Profiling of Muscle Stem Cells Identifies Novel Regulators of

Postnatal Myogenesis.

Front. Cell Dev. Biol. 4:58.

doi: 10.3389/fcell.2016.00058

\author{
Sonia Alonso-Martin 1, 2,3*t, Anne Rochat ${ }^{1}$, Despoina Mademtzoglou ${ }^{1,2,3}$, Jessica Morais ${ }^{1}$, \\ Aurélien de Reyniès ${ }^{4}$, Frédéric Auradé ${ }^{5}$, Ted Hung-Tse Chang ${ }^{1+}$, Peter S. Zammit ${ }^{6}$ and \\ Frédéric Relaix ${ }^{1,2,3,7,8 *}$ \\ ${ }^{1}$ Institut Mondor de Recherche Biomédicale, INSERM U955-E10, Créteil, France, ${ }^{2}$ Université Paris Est, Faculté de \\ Medecine, Créteil, France, ${ }^{3}$ Ecole Nationale Veterinaire d'Alfort, Maison Alfort, France, ${ }^{4}$ Programme Cartes d'Identité des \\ Tumeurs, Ligue Nationale Contre le Cancer, Paris, France, ${ }^{5}$ Sorbonne Universités, UPMC Univ Paris 06, INSERM UMRS974, \\ Center for Research in Myology, Paris, France, ${ }^{6}$ Randall Division of Cell and Molecular Biophysics, King's College London, \\ London, UK, ${ }^{7}$ Etablissement Français du Sang, Créteil, France, ${ }^{8}$ APHP, Hopitaux Universitaires Henri Mondor, DHU Pepsy \\ and Centre de Référence des Maladies Neuromusculaires GNMH, Créteil, France
}

Skeletal muscle growth and regeneration require a population of muscle stem cells, the satellite cells, located in close contact to the myofiber. These cells are specified during fetal and early postnatal development in mice from a Pax3/7 population of embryonic progenitor cells. As little is known about the genetic control of their formation and maintenance, we performed a genome-wide chronological expression profile identifying the dynamic transcriptomic changes involved in establishment of muscle stem cells through life, and acquisition of muscle stem cell properties. We have identified multiple genes and pathways associated with satellite cell formation, including set of genes specifically induced (EphA1, EphA2, EfnA1, EphB1, Zbtb4, Zbtb20) or inhibited (EphA3, EphA4, EphA7, EfnA2, EfnA3, EfnA4, EfnA5, EphB2, EphB3, EphB4, EfnBs, Zfp354c, Zcchc5, Hmga2) in adult stem cells. Ephrin receptors and ephrins ligands have been implicated in cell migration and guidance in many tissues including skeletal muscle. Here we show that Ephrin receptors and ephrins ligands are also involved in regulating the adult myogenic program. Strikingly, impairment of EPHB1 function in satellite cells leads to increased differentiation at the expense of self-renewal in isolated myofiber cultures. In addition, we identified new transcription factors, including several zinc finger proteins. ZFP354C and ZCCHC5 decreased self-renewal capacity when overexpressed, whereas ZBTB4 increased it, and ZBTB20 induced myogenic progression. The architectural and transcriptional regulator HMGA2 was involved in satellite cell activation. Together, our study shows that transcriptome profiling coupled with myofiber culture analysis, provides an efficient system to identify and validate candidate genes implicated in establishment/maintenance of muscle stem cells. Furthermore, tour de force transcriptomic profiling provides a wealth of data to inform for future stem cell-based muscle therapies.

\footnotetext{
Keywords: skeletal muscle, myogenesis, satellite cells, ephrins, zinc fingers
} 


\section{INTRODUCTION}

During vertebrate development, successive phases of embryonic and fetal myogenesis leads to formation and growth of skeletal muscles (Relaix et al., 2005; Relaix, 2006; Buckingham and Relaix, 2007). Skeletal muscle cells of trunk and limbs in mouse originate from the early somites, which appear at mid-gestation from undifferentiated presomitic mesoderm (Tajbakhsh and Buckingham, 2000). Following several steps of somite maturation, a population of muscle progenitor cells (MPC) that express the paired-box/homeobox transcription factors Pax3 and Pax7 emerge in the central region of the developing somite. Similar cell populations are also found in head muscles, though using a different set of transcriptional regulators (Sambasivan et al., 2011). MPC will both self-renew and give rise to all skeletal muscles via activation of a family of four musclespecific bHLH transcription factors (Myf5, Mrf4, MyoD, and Myog: myogenin) that induce the myogenic program (Bismuth and Relaix, 2010; Murphy and Kardon, 2011). Around birth, while all MPC maintain the expression of Pax7, Pax3 expression in only maintained in a subset of muscles (Relaix et al., 2006) (unpublished observations). MPC become in close contact with the muscle fibers in response to different signals, such as those from the Notch pathway (Seale et al., 2000; Zammit et al., 2006a; Tajbakhsh, 2009; Brohl et al., 2012). During establishment of this anatomical niche, emerging satellite cells acquire stem cellspecific characteristics, including self-renewal capacity (Mauro, 1961; Zammit et al., 2006a; Relaix and Marcelle, 2009). During postnatal muscle growth, satellite cells supply myonuclei to maturing myofibers up to approximately postnatal day 21 (P21) before becoming mitotically quiescent (Lepper et al., 2009; White et al., 2010). Adult satellite cells can be activated from their mitotically quiescent state upon injury (Wang and Rudnicki, 2011; Relaix and Zammit, 2012), to proliferate, and co-express $M y o D$ and Pax7. They then differentiate via activation of Myog (and down-regulation of $P a x 7$ ) to repair damaged myofibers, while a subpopulation of satellite cells will self-renew to restore the pool of quiescent satellite cells by down-regulation of $M y o D$ (Zammit et al., 2004; Rudnicki et al., 2008; Relaix and Zammit, 2012).

Understanding regulation of myogenic progression from MPCs to muscle stem cells is central to building a comprehensive model of satellite cell function. Many transcriptional networks that control embryogenesis are also important for myogenesis, such as Notch, BMP (bone morphogenetic protein) or WNT proteins (Linker et al., 2003; Ono et al., 2011; Brohl et al., 2012). Furthermore, a balance between extrinsic cues and intracellular signaling pathways, such as IGF, FGF, Notch, and TGF- $\beta$, is required to preserve stem cell function (Brack et al., 2008; Kuang et al., 2008; Brack and Rando, 2012; Dumont et al., 2015).

We have characterized the dynamics of skeletal muscle progenitor and postnatal stem cells from embryonic development to adult life, hence deciphering the intrinsic molecular pathways involved in specification and regulation of these muscle stem cells. Using this large microarray analysis of myogenic progenitors and stem cells during development and adult myogenesis, we identified and evaluated several new candidate factors mediating satellite cell specification and function, with a focus here on EPHB1 and several transcriptional regulators, including four zinc finger transcription regulators (Zfp354c, Zcchc5, Zbtb4, and Zbtb20) and HMGA2, co-regulator belonging to the HMGI family of small high-mobility-group (HMG) proteins (Zhou et al., 1995).

\section{Eph Receptors and Ephrin Ligands}

$\mathrm{Eph} /$ ephrin signaling has been shown to regulate muscle satellite cell motility and patterning (Stark et al., 2011), but has not been linked with regulation of the myogenic program, except for one recent study implying promotion and maintenance of slow muscle fiber identity postnatally (Stark et al., 2015). Eph receptors belong to a large family of receptor tyrosine kinases (RTK) involved in cell contact-dependent signaling and patterning (Pitulescu and Adams, 2010). EPHs are classified as EphAs or EphBs based on their binding affinity for the ephrin ligands, ephrin-A (EFNA) or ephrin-B (EFNB) (Figures S1A,B). EFNAs are GPI (glycosylphosphatidylinositol)-anchored and lack a cytoplasmic domain while EFNBs are attached to the membrane by a single transmembrane domain containing a short cytoplasmic PDZ-binding motif (Pasquale, 2005). Interestingly, both Eph receptors and ephrin ligands are competent to signal following interaction (forward and reverse signaling, respectively), and both trans and cis signaling have been described (Arvanitis and Davy, 2008; Pitulescu and Adams, 2010). In addition, Eph/ephrin signaling is often part of a complex signaling network of regulatory pathways, for instance with adhesion molecules, other cell surface receptors or channels and pores (Arvanitis and Davy, 2008).

Eph/ephrin interaction leads to a large set of developmental processes and biological responses, including adhesion and repulsion, increased or reduced motility, cell plasticity, permeability and morphogenesis, and cell fate specification (Palmer and Klein, 2003; Arvanitis and Davy, 2008). Eph/ephrins are also implicated in regulation of stem cell niches and cancer (Genander and Frisen, 2010; Murai and Pasquale, 2010; Pasquale, 2010).

\section{Zinc Finger Transcription Factors}

Zinc finger proteins belong to a large family of transcription regulators subdivided in seven categories. There are about 800 zinc finger transcription factors in the human genome, with a third of those containing a KRAB (Krüppel Associated Box) domain, such as ZFP354C (see below) or related sequences as ZBTB4 or ZBTB20 (Lupo et al., 2013). KRAB is the most widespread family of transcription factors in the human genome, but is also found in yeast (S. cerevisiae) and worm (C. elegans) (Ganss and Jheon, 2004). The KRAB protein domain is a powerful repression region that acts as a transcriptional repressor, allowing the binding to co-repressor proteins (Urrutia, 2003). KRAB-containing proteins involved in cell proliferation, differentiation, apoptosis, and tumor formation have been described (Urrutia, 2003; Tian et al., 2006; Li et al., 2008).

Zfp354c (Kid3, AJ18) belongs to the Kid family of genes. The corresponding proteins Kid1, Kid2, and Kid3, share a very similar structure: a KRAB domain and 11-13 C2H2 motifs (Figure S1C), 
these last zinc finger motifs consisting of two cysteine and two histidine residues bonded tetrahedrally to a Zinc ion (Ganss and Jheon, 2004). ZFP354c has been previously described as abundant in the brain (Watson et al., 2000), but its expression has not been tested in skeletal muscle. Interestingly, KRAB/C2H2 zinc finger protein ZFP354C participates in the BMP signaling pathway (Jheon et al., 2003), a key regulator of skeletal muscle development and stem cell function (Amthor et al., 1998; Wang et al., 2010; Ono et al., 2011; Sartori et al., 2013). Given the important role of BMP signaling in skeletal muscle biology, $\mathrm{ZFP354C}$ is a good candidate as possible regulator of myogenesis.

Zinc finger and BTB domain-containing protein 4 (Zbtb4, KAISO-L1, Znf903) is a transcriptional repressor of specificity protein (Sp) transcription factors (Sreevalsan and Safe, 2013), that binds methylated DNA to repress transcription (Filion et al., 2006; Weber et al., 2008). Despite its broad distribution, ZBTB4 is particularly expressed in the brain. In addition, examination of publicly available microarray data sets demonstrated an inverse relationship in the prognostic value and expression of ZBTB4 and the histone methyltransferase EZH2 in tumors from breast cancer patients (Yang et al., 2014). Indeed, polycomb group protein EZH2 controls self-renewal and safeguards the transcriptional identity of skeletal muscle stem cells (Juan et al., 2011).

Zinc finger and BTB domain-containing protein 20 (Zbtb20, $D P Z F, H o f, Z f p 288)$ is a member of a subfamily of zinc finger proteins containing $\mathrm{C} 2 \mathrm{H} 2$ Krüppel-type zinc fingers and BTB/POZ domains (Mitchelmore, 2002). ZBTB20 can function as a transcriptional repressor and plays an essential role in the specification of pyramidal neurons in the developing hippocampus (Nielsen et al., 2007), and promotes astrocytogenesis during neocortical development (Nagao et al., 2016). ZBTB20 is also a regulator of terminal differentiation of hypertrophic chondrocytes (Zhou et al., 2015). This factor has been recently described to be involved in liver regeneration (Weng et al., 2014), and promoting cell proliferation and tumor growth through repression of FOXO1 (Zhao et al., 2014; Kan et al., 2016). Zbtb20 null mice exhibit severe postnatal growth retardation, metabolic dysfunction and lethality, suggesting that ZBTB20 plays non-redundant roles in multiple organ systems (Sutherland et al., 2009; Cao et al., 2016).

Zinc finger, CCHC domain-containing 5 (Zcchc5, Mar3, Zhc5) belongs to the family of the gag-like retrotransposon genes (glycosaminoglycans) exclusively found in mammals, and is considered an ortholog of Ty3/gypsy group. Zcchc5 is located on the $\mathrm{X}$ chromosome, within the dystrophin (Dmd) locus (X21.1) in man. The retrotransposition capacity of these genes seems to have been lost, despite retaining an intact reading frame (Brandt et al., 2005). Thus, the retrotransposons of this family are considered as neogenes with new functions, but their impact and regulation is still poorly understood. Zcchc5 encodes a nuclear protein containing a $\mathrm{CX}_{2} \mathrm{CX}_{4} \mathrm{HX}_{4} \mathrm{C}$ DNA-binding motif, also called CCHC domain, allowing DNA binding to regulate transcription. Furthermore, the proteins of the family of genes Mart, which includes Zcchc5, have been implicated in the control of cell proliferation and apoptosis in cell lines of liver cancer whereas some become up-regulated in regenerating mouse liver
(Okabe et al., 2003; Brandt et al., 2005). Interestingly, Zcchc5 is expressed in skeletal muscles of the limbs (Diez-Roux et al., 2011) (www.eurexpress.org).

\section{Architectural Factor HMGA2 (HMGI-C)}

HMGA2, also called HMGI-C, is a transcriptional co-regulator belonging to the HMGI family of small high-mobility-group (HMG) proteins containing AT-hook DNA binding domains (Zhou et al., 1995). HMGI proteins modulate gene expression by altering chromatin architecture and/or by recruiting other proteins to the transcription regulatory complex (Thanos and Maniatis, 1992; Zhou and Chada, 1998; Pfannkuche et al., 2009). Hmga2 is highly expressed during embryonic development and down-regulated in most adult tissues (Zhou et al., 1995; Pfannkuche et al., 2009; Ashar et al., 2010). HMGA2 plays an important role in maintaining adult stem/progenitor cells, notably in maintaining neural stem/progenitor cells (Nishino et al., 2008). Hmga2 is also highly expressed in proliferating skeletal myoblasts during myogenesis, modulating satellite cell activation and proliferation both in vivo and in vitro (Li et al., 2012). Hmga2 knockout mice exhibit impaired muscle development and reduced myoblast proliferation, while overexpression of $\mathrm{Hmga} 2$ promotes myoblast growth preventing myoblast differentiation ( $\mathrm{Li}$ et al., 2012). Thus, HMGA2 is a key regulator of satellite cell activation and skeletal muscle development.

\section{METHODS}

\section{Mice}

$\mathrm{Pax}^{\mathrm{GFP} /+}$ mice (Relaix et al., 2005) were used to isolate MPC by fluorescent activated cell sorting (FACS) of the $\mathrm{GFP}+$ cells. $\mathrm{Pax} 3^{\mathrm{Cre} /+}$ mutant mice were kindly provided by Jonathan A. Epstein (Engleka et al., 2005). R26 ${ }^{m T-m G}$ mice were obtained from The Jackson Laboratory (Stock No: 007576) (Muzumdar et al., 2007). For myofiber cultures C57BL/6J (Janvier ${ }^{\circledR}$ ) male mice (8 weeks old) were used. For lineage tracing experiments, $\mathrm{Pax} 3^{\mathrm{Cr} /+}$ mice were crossed with $\mathrm{R} 26^{m T-m G}$ to obtain $\mathrm{Pax} 3^{\mathrm{Cre} /+}$; $R 26^{m T-m G}$ double mutant mice.

All animals were maintained inside a barrier facility, and all in vivo experiments were performed in accordance with the French and European Community guidelines for the care and use of laboratory animals (Project No: 01427.03 approved by MESR and File No: 15-018 from the Ethical Committee of Anses/ENVA/UPEC).

\section{Fluorescent Activated Cell Sorting}

Trunk muscle samples (intercostal, pectoral and abdominal) were isolated from the trunk as indicated in Figure 1A, at different stages during development and after birth. Muscle were minced and digested in $0.1 \%$ Trypsin (Life Technologies ${ }^{\circledR}$ ) and $0.1 \%$ Collagenase D (Roche ${ }^{\circledR}$ ) in DMEM High Glucose without phenol red (Life Technologies ${ }^{\circledR}$ ). Digested muscles after filtration were cell-sorted by flow cytometry using a FACS Aria II, using FITC channel to recover the GFP+ cells from $P a \times 3$ GFP/+ mice. GFP+ cells were stained using propidium iodide to exclude dead cells (Figure S2A). 


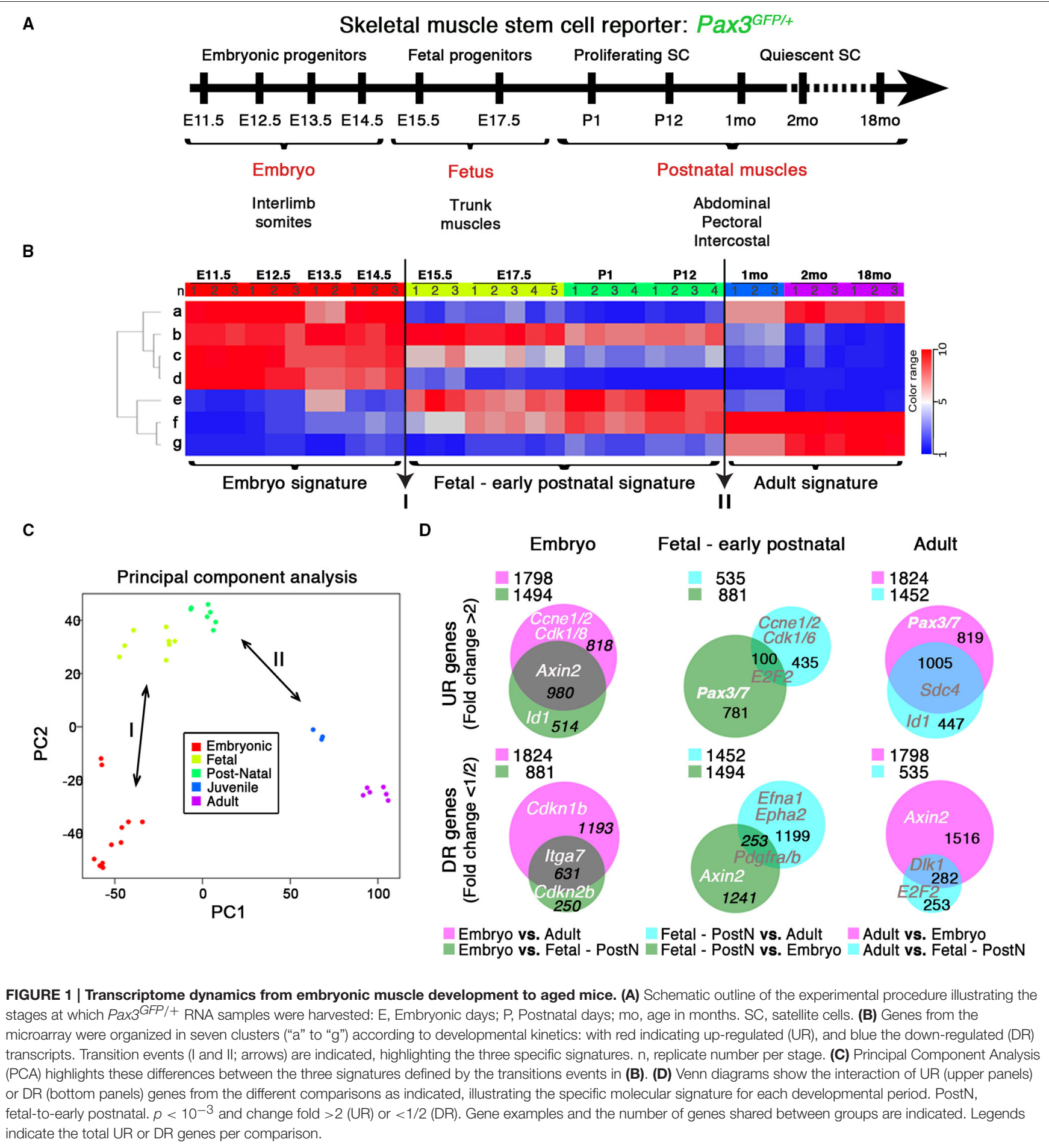

\section{qPCR Analysis}

RNA from trunk muscles was isolated through the RNeasy Fibrous Tissue kit (Qiagen ${ }^{\circledR}$ ). For C2C12, total RNA extraction was performed using the RNeasy mini kit from Qiagen ${ }^{\circledR}$. Total mRNA content was transcribed into coding DNA (cDNA) according to Transcriptor First Strand cDNA Synthesis kit
(Roche ${ }^{\circledR}$ ) protocols. Quantitative analyzes were performed using the SYBR-Green kit (Roche ${ }^{\circledR}$ ). APCR was performed on biological duplicates (by sorting two different embryo series) with technical duplicates. The results obtained were analyzed by calculating the $2^{\wedge}-\Delta \mathrm{Ct}$. Hprt1 was used as reference gene. 
Oligonucleotides of the following genes were selected, tested and verified according to their efficiencies and specificities:

\section{EphB1: FWD 5' - CCGTGGATGACTGGCTAAGT - 3' REV $5^{\prime}$ - TACCGATGGTGACTGGTTCA - $3^{\prime}$ \\ Zbtb4: FWD $5^{\prime}$ - CGCTTCTCCATGTTGGCTAT - $3^{\prime}$ REV $5^{\prime}$ - GTGAGCAGGGAACTTGGTGT - $3^{\prime}$ \\ Zbtb20: FWD 5' - AATGCGAAAGGGAAGCAGTA - $3^{\prime}$ REV 5' - ACAGGACCCGTGGAGTAATG - $3^{\prime}$}

\section{RNA Preparation, cDNA Synthesis, and Microarray Hybridization}

Microarray processing was performed by PartnerChip (Evry, France), according to NuGEN (http://www.nugen.com/ products/microarray-qpcr\#cdna-generation) and Affymetrix (http://www.affymetrix.com/support/technical/manuals.affx) protocols. Briefly, total RNA from FACS-sorted trunk muscle GFP+ cells was extracted from independent experiments according to the RNeasy ${ }^{\circledR}$ Micro Kit (QIAGEN) RNA extraction protocol. RNA samples were cleaned using Qiagen RNAeasy mini-columns and their quality assessed by spectrophotometry (Nanodrop ND-1000). Total RNA was analyzed on Agilent microarrays (Bioanalyzer, 2100) to assess integrity of ribosomal RNA ( $28 \mathrm{~S}$ and $18 \mathrm{~S}$ peaks). Synthesis and amplification of cDNA was performed following NuGEN Ovation Pico WTA System protocol, and 100 ng of total RNA were used for first strand cDNA synthesis. Second strand was synthesized following the Ribo-SPIA technology developed by NUGEN. Five micro gram of single-stranded cDNA was fragmented and a biotinlabeled nucleotide was attached to the $3^{\prime}$ end of each fragment (Encore Biotin Module, NuGEN). High-density oligonucleotide arrays containing 45,000 sets of oligonucleotide probes $(25 \mathrm{~m})$ that cover all 30,000 genes encoded by the murine genome (Affymetrix Mouse Genome 4302.0 Arrays, Ref 900495) were used for gene expression detection. Hybridization during $16 \mathrm{~h}$ at $45^{\circ} \mathrm{C}$ in a rotary oven (Affymetrix), washing and staining (GeneChip ${ }^{\circledR}$ Fluidics Station 450) and scanning (GeneChip Scanner 3000) were carried out according to NuGEN and Affymetrix protocols. Expression Console software (Affymetrix) was used for image analysis and to determine probe signal levels. The quality and statistical analysis of the data were finally made using the GeneSpring GX11 analysis software (Agilent Technologies).

\section{Expression Microarray Analysis}

\section{Pre-Treatment}

Expression profiles of 36 samples (Pax3GFP+ cells at different stages during development and after birth) were obtained using Affymetrix Mouse Genome 4302.0 Arrays. Expression profiles were normalized in batch using RMA algorithm (affy $\mathrm{R}$ package) yielding a (probe sets, samples) matrix. As the 36 samples were obtained by merging two series including 15 and 21 samples, Combat algorithm (Johnson WE-Biostatistics2007) was used to normalize the corresponding batch effect. Expression profiles were aggregated by Gene Symbol (mean across probe sets) using Affymetrix csv annotation file (na32 version).

\section{Unsupervised Analysis}

The gene expression matrix (GEO Series GSE63860) was then row-mean-centered. The resulting matrix was used for unsupervised classification of the genes. Genes $(n=21678)$ were partitioned in ten clusters using the kmeans classification algorithm. The biggest cluster $(n=8896)$ contained genes showing almost no variation across all samples: it was eliminated from further analysis. Three clusters were found to be highly correlated (centroids correlation $>0.95$ ) and were merged in a unique gene cluster (cluster g, Figure 1B). We thus remained with seven clusters. For each sample, the mean expression of all the genes of each cluster was calculated, yielding a (seven clusters, 36 samples)-matrix shown in Figure 1B.

\section{Supervised Analysis}

Moderate $T$-tests (as implemented in limma $\mathrm{R}$ package) were used to identify differentially expressed genes.

\section{Pathways Analysis}

To analyze the pathway enrichment, hypergeometric tests were used, taking as "pathways" the terms (and related murine genes) from the Gene Ontology (GO) (http://www.geneontology. org) and the murine KEGG pathways (www.genome.jp/kegg). Pathways enrichment in the seven gene clusters: in each of the seven gene clusters, the pathway analysis was performed using (i) all the genes included in the cluster, (ii) genes selected based on their coefficient of variation and medianabsolute-deviation (different thresholds were used): the minimal (hypergeometric test) $p$-value obtained from these different (sub-) lists was retained. Pathways enrichment analysis of differentially expressed genes: given a comparison between two groups of samples, yielding a $p$-value and a fold change for each gene, several lists of differentially expressed genes were selected* and the minimal (hypergeometric test) $p$-value obtained from these different lists was retained. $\left.{ }^{*}\right)$ Lists of differentially expressed genes: genes yielding a (moderate $T$-test) $p>1 \mathrm{e}-5$ were removed from the analysis; remaining genes were ordered based on the fold change; the $\mathrm{n}$ genes with highest (respectively lowest) fold change were selected as a separate list; the $n / 2$ genes with highest fold change and the $\mathrm{n} / 2$ genes with lowest fold change were merged in another list; this operation was performed for several values of $n(200,300,400,500,750$, and 1000). Principal component analysis (PCA) of the expression profiles was performed using $\mathrm{R}$ software. Venn diagrams and pathway interaction schemes were generated applying BioVenn (http://www.cmbi.ru.nl/cdd/biovenn/) and GOrillaREViGO (http://cbl-gorilla.cs.technion.ac.il/) software packages, respectively. Pathway analysis was completed employing DAVID Bioinformatics Resources 6.7 (http://david.abcc.ncifcrf.gov/).

\section{Comparative Analysis of Microarray Data with Published Available Datasets}

Data normalization was performed with frozenRMA and corrected for batch effect using Combat algorithm (Johnson WE-Biostatistics-2007). Combined data series were the 36 samples from our study and those from published datasets GSE50821 (Sinha et al., 2014) and GSE47177 (Liu et al., 2013). 
The three Affymetrix series were used to compared adult vs. old expression profiles (supervised meta-analysis young[2 months] vs. old $[>=18$ months]). This analysis showed that the combination of the three sets found $32 \%$ significantly deregulated genes and in the same direction of deregulation $(32 \%$ $=$ proportion of the combined test under $\mathrm{H} 1=$ Test Stouffer).

\section{Accession Numbers}

The complete microarray data set, including the RMA data used to produce intensity maps, have been deposited in NCBI's Gene Expression Omnibus, and are accessible through GEO Series accession number GSE63860 (http://www.ncbi.nlm.nih.gov/geo/ query/acc.cgi? acc $=$ GSE63860).

\section{Cloning (GMO Project No: 371)}

To target activated satellite cells and not myofibers in our ex vivo assays, a replication-deficient retrovirus, MIGR ( $p M S C V$ IRES-eGFP), has been used to transduce proliferating cells and overexpress either dominant negative (DN) EphB1, Zbtb4, and Zbtb20 or full-length cDNA for Zfp354c, Zcchc5, Zbtb4, Zbtb20, and Hmga2 (Pear et al., 1998; Zammit et al., 2006b). The virus is composed, besides the $5^{\prime}$ and $3^{\prime}$ LTR of the MSCV virus, the latter being mutated to prevent replication, and the phi integrase, of a multicloning site followed by an IRES-eGFP sequence to track infected cells by fluorescence. This tracking cassette was later modified into MISSINCK by substituting eGFP with an insulin signal sequence-Cyan Fluorescent Protein (CFP)-KDEL sequence in order to restrict fluorescent tracker expression to the endoplasmic reticulum and Golgi.

\section{Isolated Myofiber Cultures}

Culture of single fibers was performed according to previously described strategies (Moyle and Zammit, 2014). Briefly, dissected EDL muscles were digested in a filtered solution of $0.2 \%$ collagenase (SIGMA-ALDRICH ${ }^{\circledR}$ ) in DMEM High Glucose/1\% L-Glutamine/1\% Penicillin/Streptomycin (Life Technologies ${ }^{\circledR}$ ) (isolation medium). After $2 \mathrm{~h}$ of connective tissue digestion, EDLs were mechanically dissociated fiber by fiber. Quiescent satellite cells on the isolated myofibers were activated by a solution of $10 \%$ horse serum $/ 0.5 \%$ chicken embryo extract in filtered isolation medium. Contracted fibers were removed.

\section{Retrovirus Production and Myofiber Infection}

Retroviral particles (see Cloning) were produced in HEK293T cells by transfection using FuGENE ${ }^{\circledR}$ with a helper virus, which contains the necessary elements to obtain the correct encapsidation and active retrovirus (phi integrase, gag, pol and env (VSV-g) genes). We collected the supernatants after transfection at $\mathrm{T}=72 \mathrm{~h}$ and $\mathrm{T}=84 \mathrm{~h}$, which displayed the highest retroviral particle titers.

After $24 \mathrm{~h}$ of activation, myofiber-attached satellite cells were infected with the retroviral particles diluted $1 / 10.48 \mathrm{~h}$ afterwards $(\mathrm{T}=72 \mathrm{~h}$ ), fibers were fixed to proceed with immunofluorescence analysis.

\section{C2C12 Cell Culture for Muscle Differentiation and Infection}

Myogenic differentiation was induced according to previously reported protocols (McMahon et al., 1994). Murine C2C12 cells were cultured in $10 \%$ fetal bovine serum (Bio West ${ }^{\circledR}$ ) in High Glucose DMEM (Life Technologies ${ }^{\circledR}$ ) for proliferation assay (GM). Differentiation was induced by switching into medium supplemented with $2 \%$ horse serum (Promega ${ }^{\circledR}$ ) in High Glucose DMEM (DM), generating multinucleated myotubes surrounded by mononuclear reserve cells.

For retroviral infection, $10^{4} \mathrm{C} 2 \mathrm{C} 12$ cells were plated in GM and incubated with undiluted retroviral supernatant containing $4 \mu \mathrm{g} / \mathrm{mL}$ polybrene (SIGMA-ALDRICH ${ }^{\circledR}$ ) for 3-4 h. Retroviral medium was then removed, and the cells washed and incubated in either proliferation (for PH3, KI67, EdU, and MYOD analysis) or differentiation (for MYOG analysis) medium.

\section{Immunostaining}

\section{Satellite Cells on Myofibers and Cryosections}

Myofibers were fixed in 4\% paraformaldehyde for $10 \mathrm{~min}$, treated with $0.5 \%$ triton and blocked in $10 \%$ goat serum $/ 10 \%$ swine serum (Moyle and Zammit, 2014). The following antibodies were used: EPHB1 (Rabbit Abcam ${ }^{\circledR}$ ab5414) 1/100, PAX7 monoclonal $\left(\mathrm{DSHB}^{\circledR}, \mathrm{PAX}^{\circledR}-\mathrm{c}\right) 1 / 50$, MYOD monoclonal $\left(\mathrm{DAKO}^{\circledR}\right.$, clone 5.8A, M3512) 1/60, MYOD (Rabbit Santa Cruz Biotech ${ }^{\circledR}$, sc-760) 1/50, MYOG monoclonal (DSHB ${ }^{\circledR}$, F5D) 1/50, CD-31 (PECAM1) (Rat BD Pharmigen ${ }^{\circledR}$, 550274) $1 / 500$, and GFP (Rabbit Life Technologies ${ }^{\circledR}$ ) $1 / 500$, or (Chicken Abcam ${ }^{\circledR}$ ab13970) 1/200. Secondary antibodies employed to reveal the staining were Alexa 594 goat anti-mouse IgG $(\mathrm{H}+\mathrm{L})$, Alexa 488 goat anti-rabbit IgG $(\mathrm{H}+\mathrm{L})$ (Life Technologies $\left.{ }^{\circledR}\right)$, and DyLight-405 donkey antichicken IgY (IgG) $(\mathrm{H}+\mathrm{L})$, and Cy5-Goat Anti-Rabbit IgG $(\mathrm{H}+\mathrm{L})$ (Jackson ImmunoResearch ${ }^{\circledR}$ ). Nuclei were counterstained with DAPI.

\section{C2C12 Cultured Myoblasts}

The following antibodies were used: MYOD, MYOG, and GFP (as above), PH3 (Rabbit Merck-Millipore ${ }^{\circledR}, 06-570$ ) 1/50, Ki67 (BD Pharmigen ${ }^{\circledR}$, 556003) 1/150, HA (Rabbit Sigma-Aldrich ${ }^{\circledR}$, H6908) $1 / 400$, and GFP monoclonal (Sigma ${ }^{\circledR}$ ) $1 / 50$. Secondary antibodies included Alexa 488 goat anti-mouse $\operatorname{IgG}(\mathrm{H}+\mathrm{L})$, Alexa 594 goat anti-mouse IgG $(\mathrm{H}+\mathrm{L})$, Alexa 488 goat antirabbit IgG $(\mathrm{H}+\mathrm{L})$, Alexa 594 goat anti-rabbit IgG $(\mathrm{H}+\mathrm{L})$ (Life Technologies $\left.{ }^{\circledR}\right)$. EdU reaction was performed with Click-iT ${ }^{\circledR}$ EdU Alexa Fluor ${ }^{\circledR} 647$ Imaging Kit (ThermoFisher Scientific ${ }^{\circledR}$ ). Nuclei were counterstained with DAPI.

\section{Imaging and Statistics}

Analysis was carried out using a Leica TCS SPE confocal microscope. Images were processed with either Adobe Photoshop CS5 software (Adobe Systems) or ImageJ (version 1.47v; National Institutes of Health, USA, http://imagej.nih.gov/ij).

Infected satellite cells in myofiber cultures were directly counted under a Leica fluorescent microscope at 40x and 100x magnification.

Mean \pm standard error (SEM) was given. The single $\left(^{*}\right)$, double $\left(^{* *}\right)$ and triple $\left({ }^{* * *}\right)$ asterisks represent $p$-values $p<0.05$, 
$p<0.01$, and $p<0.001$ respectively by Student's unpaired $t$-test or Mann-Whitney $U$-test. All experiments have been performed on at least three independent experiments for each condition.

Supplementary Movies were performed using a DSD2 Workstation with Imaris software (ANDOR).

\section{RESULTS}

\section{Expression Dynamics of Skeletal Muscle Stem Cells}

Pax3 is expressed in fetal progenitors and satellite cells of trunk hypaxial muscles (Relaix et al., 2005; Relaix, 2006; Calhabeu et al., 2013). We used a Pax3 reporter mouse to perform a chronological global profiling in embryonic, fetal and postnatal MPC and satellite cells expressing Pax3 (Figure 1A; Relaix et al., 2005).

Prospective isolation of Pax3-GFP myogenic progenitors and stem cells was performed as previously described (Figure S2A; Montarras et al., 2005; Lagha et al., 2010), taking advantage of the GFP coding sequence targeting one allele of Pax3 (Relaix et al., 2005). Pax3 is expressed in muscle progenitors but also in early migrating neural crest cells (Epstein et al., 1993). Neural crest cells give rise to many derivatives, including the peripheral nervous system, melanocytes, and a subpopulation of venous endothelial cells (by E13.5) among other cell types (Engleka et al., 2005; Stoller et al., 2008). To exclude a possible contamination of satellite cells with endothelial cells, we performed Pax3-lineage tracing using $\mathrm{Pax} 3^{\mathrm{Cre} /+} ; \mathrm{R} 26^{m T m G}$ mice (Figure S2B). While adult myogenic cells were mGFP+ (Pax3-Cre recombined), all endothelial cells remained mTOMATO+ (not recombined) (Figure S2B and Movie S1). Moreover, all CD31 (PECAM1) + endothelial cells were included within the mTOMATO+ population (Figure S2B and Movie S2). These results demonstrate that the Pax3 lineage does not contribute to skeletal muscle endothelial population, and that skeletal muscle expression of PAX3 is specific to muscle stem cells.

Since Pax3 is expressed in a subset of the Pax7-expressing satellite cells, we compared our gene expression data with previously published datasets of adult muscle stem cells where markers different from PAX3 were used to isolate satellite cells (Figure S3A; Liu et al., 2013; Sinha et al., 2014). Pax3expressing satellite cells were not significantly divergent from previously reported datasets, while embryonic and fetal/early postnatal datasets showed different specific profiles (Figure S3A). Moreover, we compared available data from adult (3-8 monthold) and old satellite cells (18-24 month-old) with our data. We identified a similar variation in all datasets, demonstrating that Pax3-expressing satellite cells do not define a subpopulation of satellite cells. Our data therefore are likely representative of the whole satellite population.

Expression profiles from 11 developmental stages were normalized, generating a GEO (GSE63860) showing the kinetics of each transcript over time (Figures 1A,B). Transcript variations were divided into seven clusters based on general expression profiles (Figure 1B and Figure S3B), which were determined to be functionally homogeneous and easily aggregated in defined GO pathways (Figure S3B, Pathways). Furthermore, this in silico analysis of the transcriptome through categorization of expression trends (Figure 1B and Figure S3B, Pathways) and specific molecular signatures (Figures 1B-D), yielded known myogenic and related factors (Figure S3B, Genes) (Kuang et al., 2008; Abou-Khalil et al., 2009; Boldrin et al., 2012; Conboy and Rando, 2012). Strikingly, two transition events were revealed: (I) from embryonic to fetal myogenesis (Messina and Cossu, 2009), hypothesized to mark the early onset of satellite cell formation (Kassar-Duchossoy et al., 2005); and (II) the acquisition of quiescence in satellite cells around 3 weeks of age (Figures 1B,C; Lepper et al., 2009; White et al., 2010). These transitions define the three major developmental states: embryonic progenitors (E11.5-E14.5), fetal-to-early postnatal (E15.5-P12) and adult quiescent satellite cells (1-18 months), each with a specific molecular signature (Figures 1B-D). Pairwise comparison between different signatures of up-regulated (UR) and downregulated (DR) transcripts revealed the genes and pathways defining each developmental period, provided in Figure S4 and Tables S1-S3 (UR), and Tables S4-S6 (DR), respectively. Importantly, this in silico analysis also provides new markers for muscle progenitor/stem cell maturation in both UR (extracellular matrix formation, anatomical structure development, immune and inflammatory responses) and DR (cell cycle and DNA repair transcripts or developmental processes) pathways.

The dynamics of our transcriptional profiling reveal that each stage of development is molecularly defined in a more progressive manner than previously recognized.

\section{Type A-Ephrins and Eph Receptors Expression during Myogenesis}

We have identified a set of transcripts specifically associated with the embryonic and fetal stages of development or the satellite cell lineage. Interestingly, Ephrin family members showed a very dynamic behavior throughout development and postnatal myogenesis, including EphAs and EfnAs (Figure 2). We could distinguish two distinct behaviors: first, a set of EphA transcripts that are up-regulated during the acquisition of muscle stem cell properties (EphA1 and EphA2, Figures 2A,B); second, an independent set that is down-regulated over the same period (EphA3, EphA4, EphA5, and EphA7, Figures 2C-F). EPHA4 has been reported to bind both EFNA and EFNB ligands subtypes (Singla et al., 2010). This receptor was expressed in the developing embryo, and repressed during postnatal growth (Figure 2D). We found that EphA4 is strongly expressed during early embryonic development (E11.5) and ceases its expression at the late fetal stage. In our transcriptome data, $E f n A 2, E f n A 3$, $E f n A 4$, and $E f n A 5$ ligands expression were also down-regulated during fetal development, being no longer expressed during aging (Figures $2 \mathbf{H}-\mathbf{K}$ ). Interestingly, only EfnA1 became upregulated during the perinatal transition that characterizes the emergence of satellite cells (Figure 2G).

\section{Type B-Ephrins and Eph Receptors Expression during Myogenesis}

Expression of EphBs and $E f n B$ s at different stages is shown in Figure 3. Among those, the transmembrane receptor EphB1 


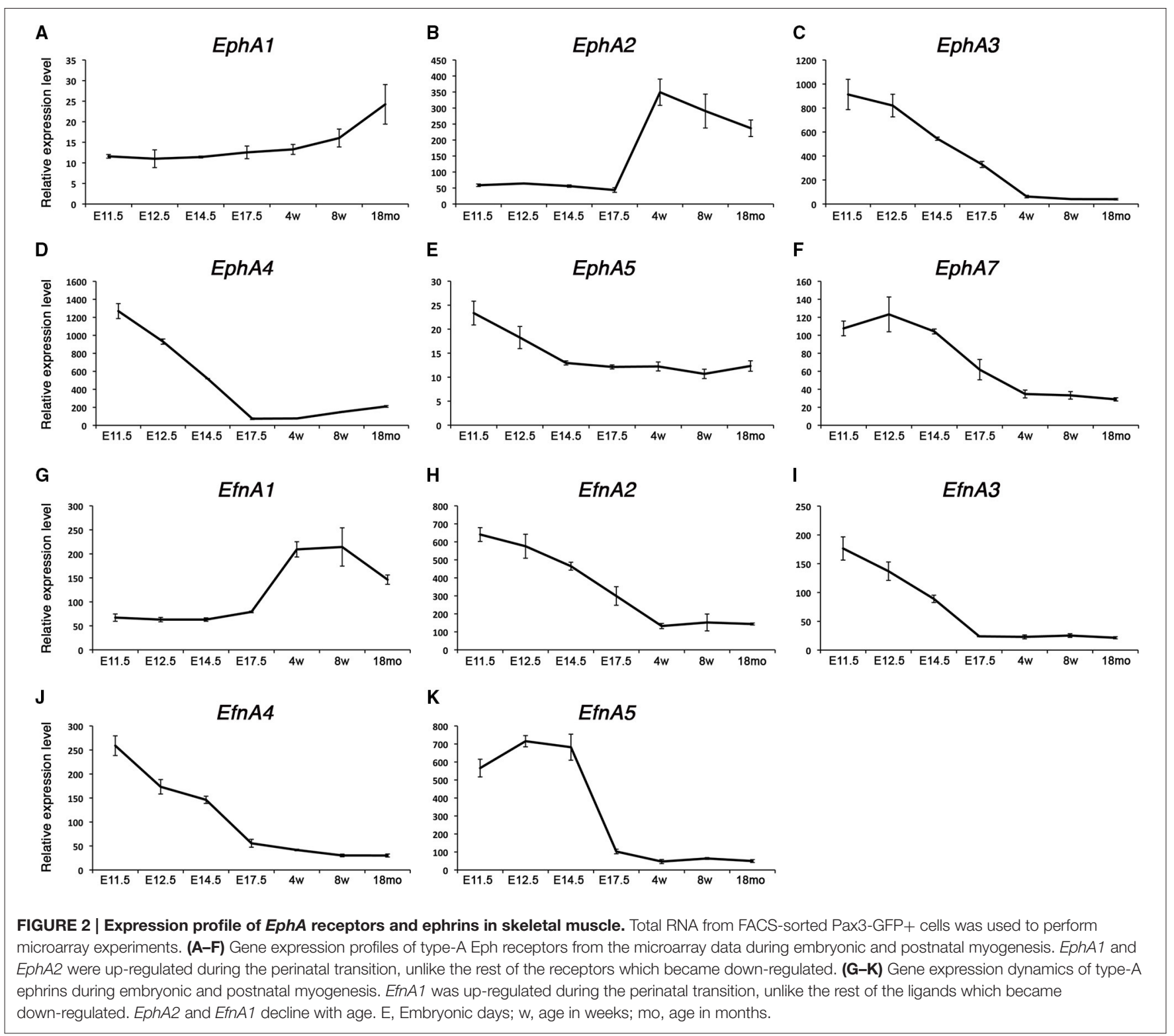

presents a unique dynamic expression profile: initially expressed early during myogenic development, then down-regulated during the fetal stage, and finally re-expressed in postnatal satellite cells (Figure 3A). By contrast, EphB2, EphB3, and EphB4 are highly expressed during early development and progressively repressed as development proceeds (Figures 3B-D). We confirmed that EphB1 was first expressed during the early stages of embryonic muscle development (Figure S5A), and down-regulated in the fetal stages. While it was weakly expressed in the early immature satellite cells (i.e., P2-P4), it was strongly up-regulated by P14, with expression then maintained, albeit at a lower level, in adult satellite cells. Interestingly, aged satellite cells (18 months old) show a marked decrease in EphB1 expression (Figure S1A), corresponding to the timing when satellite cells start losing their regenerative capacity (Sousa-Victor et al., 2014).
We used immunostaining on cultured floating myofibers to characterize expression of EPHB1 in muscle stem cells. This culture system recapitulates satellite cell activation, self-renewal and differentiation, similar to the situation observed during muscle regeneration in the adult (Zammit et al., 2004). After $72 \mathrm{~h}$, satellite cells were activated and proliferating (PAX7+ and MYOD+); some cells activated myogenin (MYOG+) and downregulated $\mathrm{PAX} 7$, thus differentiating, and other cells will adopt a divergent fate, withdrawing from cell cycle and maintaining the expression of PAX7 while down-regulating MYOD (Zammit et al., 2004). Co-immunostaining of EPHB1 with PAX7, a specific marker of satellite cells, was observed on isolated fibers (Figure 3E), in $80 \%$ of the cells. However, expression was also observed in PAX7, MYOD, and MYOG positive myogenic cells at $\mathrm{T}=72$ (Figure S5B), demonstrating that EPHB1 was not 


\section{A}

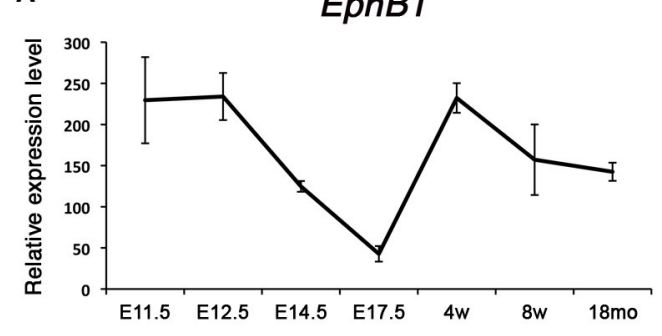

C

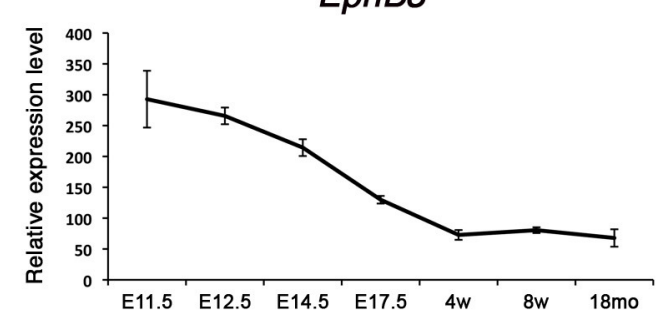

E

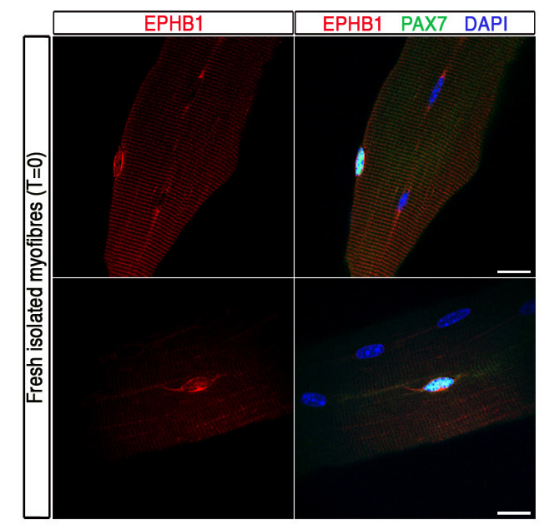

G

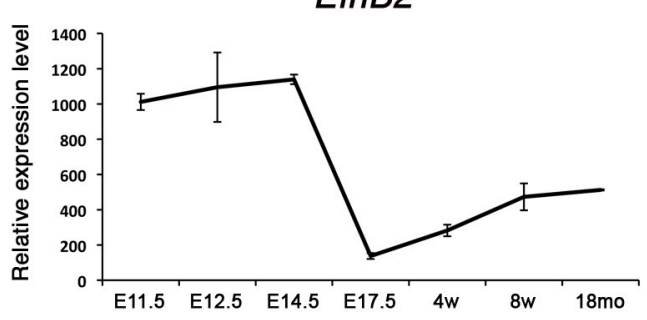

B

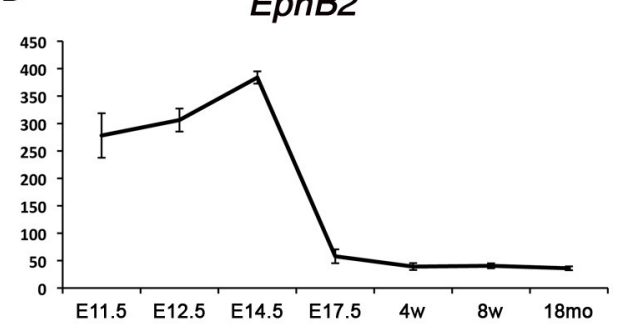

D

EphB4

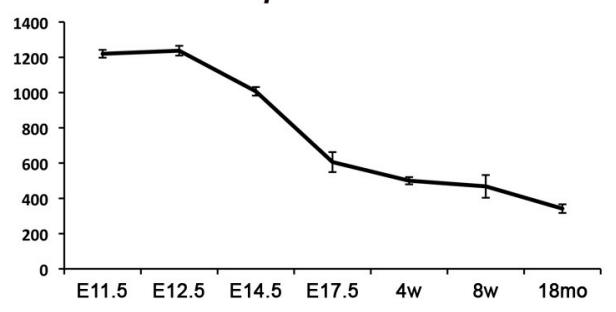

$\mathbf{F}$

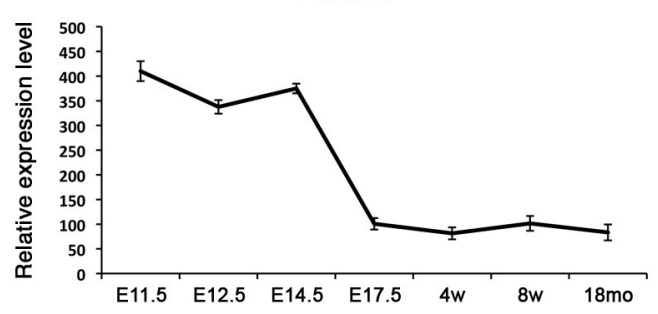

H

EfnB3

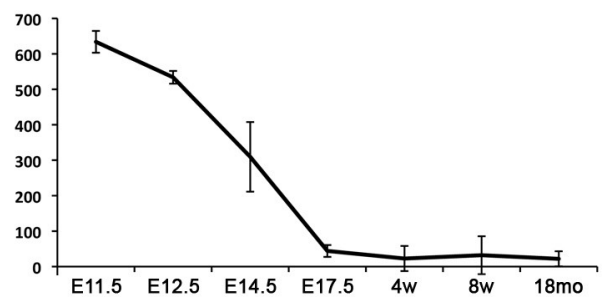

FIGURE 3 | Expression profile of EphB receptors and ephrins in skeletal muscle. Total RNA from FACS-sorted Pax3-GFP+ cells was used to perform microarray experiments. (A-D) Gene expression profiles of type-B Eph receptors during embryonic and postnatal myogenesis. EphB1 was up-regulated during the perinatal transition, unlike the rest of the receptors which became down-regulated. (E) Expression of EPHB1 receptor in quiescent satellite cells on fresh isolated EDL myofibers $(T=0)$ by co-immunostaining for EPHB1 (red) and PAX7 (green). Nuclei were labeled in blue with DAPI. Scale bars, $10 \mu \mathrm{m}$. (F-H) Gene expression dynamics of type-B ephrins during embryonic and postnatal myogenesis. All these ephrins were down-regulated during the perinatal transition. E, Embryonic days; w, age in weeks; mo, age in months.

restricted to quiescent satellite cells, but maintained during the different steps of satellite cell activation and differentiation.

Finally, the kinetics of the ligands for type B-ephrins behaved similarly to most of the type A, being down-regulated during the perinatal transition to the emergence of satellite cells (Figures 3F-H).

\section{EPHB1 Regulates Myogenesis in C2C12 Cells}

C2C12 myoblasts are a classic model to analyze skeletal muscle differentiation (McMahon et al., 1994). Proliferating C2C12 cells were maintained in mitogen-rich medium, but differentiation was induced by switching into a serum poor-medium, thereby 
inducing MYOG expression and fusion into myotubes. Under long-term differentiation conditions, a reserve cell population emerges that shares some molecular and cellular features with quiescent satellite cells: for example, reserve cells express PAX7, are mitotically quiescent and aligned to the myotubes without fusing (Yoshida et al., 1998; Olguin and Olwin, 2004; Shefer et al., 2006).

EPHB1 is expressed in both quiescent and activated satellite cells (Figures 3A,E and Figure S5). The extracellular region of the Eph receptor contains a globular ligand-binding domain, a cysteine-rich region (EGF-like motif), and two fibronectintype III repeats (Figure S1). The intracellular region contains a tyrosine kinase domain, a SAM (Sterile Alpha Motif) proteinprotein interaction domain and a C-terminal PDZ-binding motif (Figure S1A). To assess EPHB1 function in myogenic cells, we generated a dominant negative form of this receptor (EphB1DN) by removing the intracellular domain of the protein (Figure S1B) (Vindis et al., 2003, 2004; Haldimann et al., 2009; OdaIshii et al., 2010). Binding of ephrins to Eph receptors induces heterotetramers to initiate the signal cascade, which then will oligomerize and assemble in large signaling clusters (Pitulescu and Adams, 2010). EphB1 truncated receptor (EphB1DN) is therefore able to bind ephrin ligands, but cannot forward signal (Haldimann et al., 2009; Oda-Ishii et al., 2010). We induced expression of EphB1DN or control constructs using retroviralmediated delivery in the $\mathrm{C} 2 \mathrm{C} 12$ myoblastic cell line (Figure 4). EphB1DN was cloned into a modified retroviral vector carrying either an IRES-GFP or CFP to identify transduced cells and packaged using standard methods (Pear et al., 1998; Zammit et al., 2006b). These retroviral constructs were tested in $\mathrm{C} 2 \mathrm{C} 12$ and transduction of more than $90 \%$ of the cells was observed (Figure S6). Co-staining with EPHB1 antibody showed the expression of the receptor in $\mathrm{C} 2 \mathrm{C} 12$ cells (Figure S6A). As our antibody is directed against the last 10 residues of the intracellular domain, a C-terminal 3HA-tagged version of EphB1DN was generated. Figure S6B shows a similar localization to the one of EPHB1 in transduced cells.

We then assayed whether expression of EphB1DN would impact on proliferation of $\mathrm{C} 2 \mathrm{C} 12$ cells using an antibody detecting the phosphorylated form of histone $\mathrm{H} 3$ at serine 10 (PH3) (Figures 4A,B), and validated by KI67 and EdU incorporation (Figures S7A,B). By $24 \mathrm{~h}$ after infection with the EphB1DN-encoding retrovirus, C2C12 cells exhibited a significant increase in the mitotic index, suggesting either a decreased cell cycle time or a decreased myogenic commitment toward differentiation. To further characterize the role of EPHB1 during myogenic differentiation, we analyzed expression of MYOD (Figures 4C,D) and MYOG (Figures 4E,F) in C2C12 cells 48 and $72 \mathrm{~h}$ respectively after infection, and found an increased number of cells expressing these myogenic markers. We concluded that EphB1DN leads to increased proliferation and differentiation of $\mathrm{C} 2 \mathrm{C} 12$ cells, suggesting a regulatory role for EPHB1 in satellite cell quiescence.

\section{EPHB1 Is Required for Satellite Cell Function and Renewal}

We next infected primary satellite cells on muscle fibers in non-adherent cultures to assay the consequence of expressing
EphB1DN in activated satellite cells, and assayed self-renewal, proliferation and differentiation (Figure 5). $48 \mathrm{~h}$ after infection (72 $\mathrm{h}$ post isolation), the number of PAX7 + cells was reduced (Figures 5A,B). Consistently, we observed an increase in the MYOD+ (activated/proliferating and differentiating) population (Figures 5C,D). The number of MYOG+ (differentiating) cells was also increased (Figures 5E,F). Together, these results suggest that EPHB1 is involved in the maintenance of the pool of these adult stem cells, both by promoting self-renewal and reducing activation and differentiation. To appropriately assess self-renewal of satellite cells, Pax7/MyoD co-immunostaining was performed, taking advantage of a retrovirus with a CFP reporter expression restricted to the endoplasmic reticulum and Golgi (Figure 5G and Figures S6, S7). We confirmed that the decrease in the self-renewing satellite cell population (Pax7) correlated to an increase in differentiation (Figure 5G).

\section{Expression of Zinc Finger Containing Proteins during Myogenesis}

Candidate genes coding for ZFP354c and ZCCHC5 zinc finger containing proteins were repressed during the emergence of satellite cells around birth (Figures 6A,B). Down-regulation of these factors was observed in muscle progenitors at the fetal stage overlapping with the emergence of satellite cells. These two zinc finger containing-proteins were not expressed in adult and aged satellite cells. While Zfp354c was highly expressed during early myogenesis and gradually repressed from fetal stages (Figure 6A), Zcchc5 was not expressed during early embryonic myogenesis (Figure 6B), but appeared during early establishment/formation of the satellite cell pool, before being completely down-regulated during acquisition of satellite cell quiescence. According to the known functions of these factors, we can hypothesize their possible involvement during MPCs proliferation $(Z f p 354 c)$, or for a correct determination of the MPC fate to become the muscle stem cells (Zcchc5).

By contrast, two other zinc finger containing proteins $Z b t b 4$ and Zbtb20, were not expressed during development but were induced during establishment of satellite cells and acquisition of quiescence (Figures 6C,D). Moreover, high expression of these zinc finger containing-proteins was maintained in adult and aged satellite cells, implicating a possible function in maintaining quiescence of muscle stem cells. Strikingly, these factors are induced during cardiotoxin-induced muscle regeneration in vivo (Figure S8A).

\section{Effect of Zinc Finger Containing Proteins in Postnatal Satellite Cells}

We manipulated expression of Zfp354c, Zcchc5, Zbtb4, and $Z b t b 20$ using retroviral-mediated delivery in isolated myofiber cultures as above. We generated vectors carrying either a fulllength transcript for overexpression, or dominant negative forms to analyze function.

Overexpression in satellite cells of either Zfp354c or Zcchc5 maintained expression in satellite cells that no longer expressed the endogenous gene (Figures 6E-J). Notably, overexpression of $Z f p 354 c$ led to a decreased number of PAX7+ satellite cells compared to control (Figure 6E) with no apparent effect during activation (MYOD+) and differentiation (MYOG+) 
A
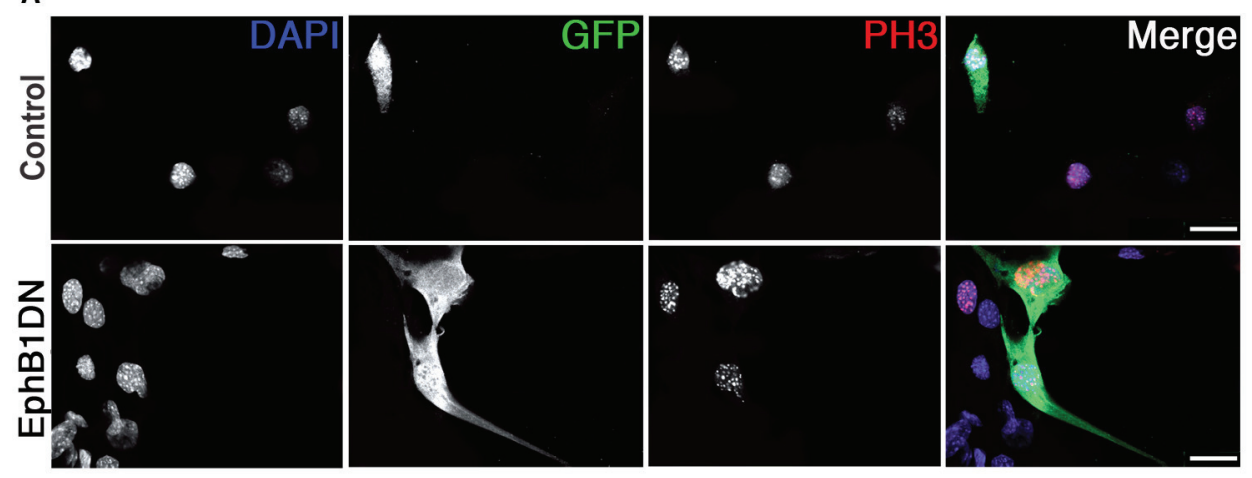

B

C

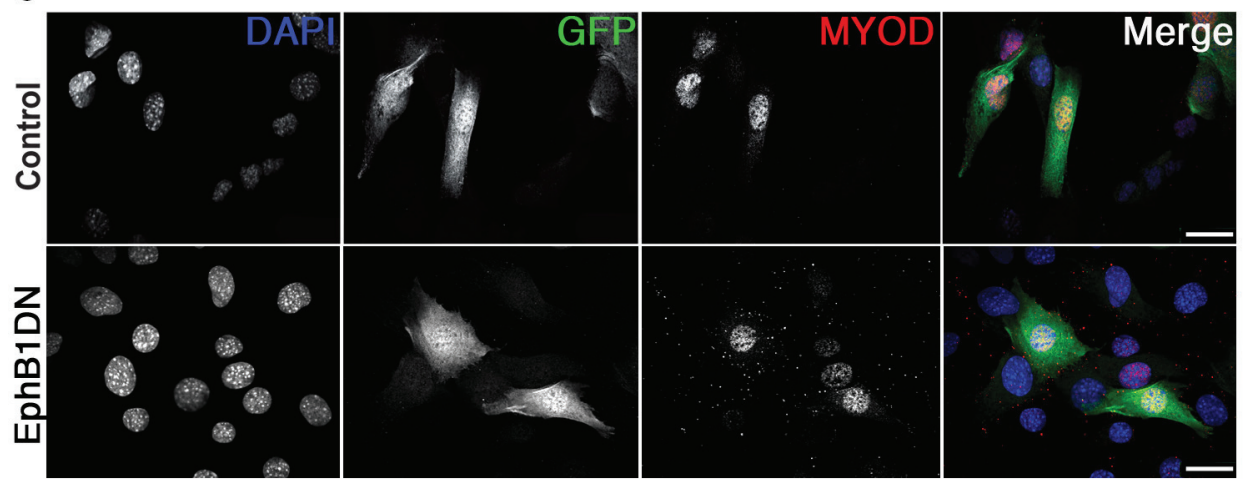

E
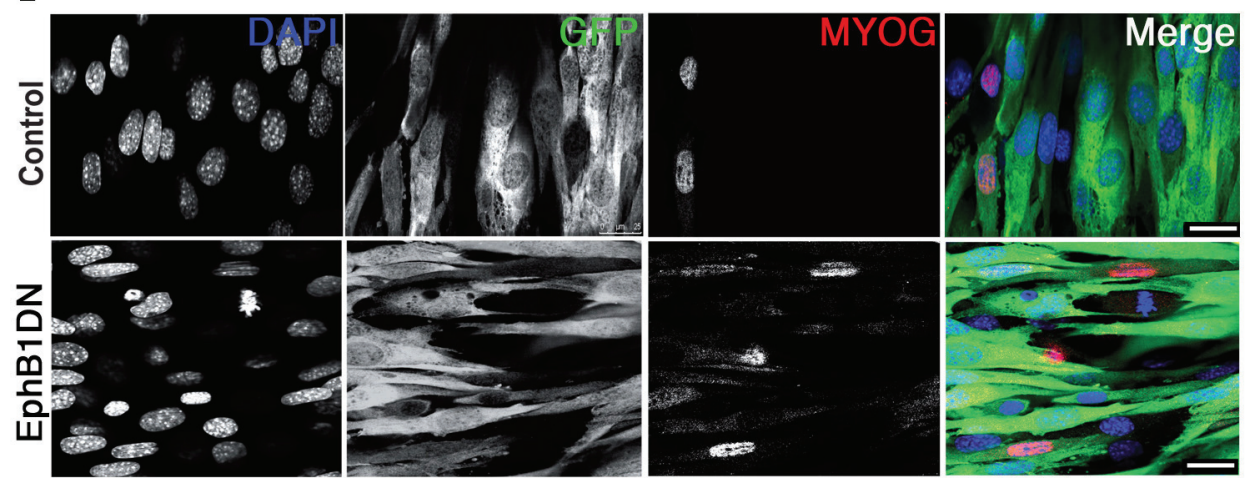

$\mathbf{F}$

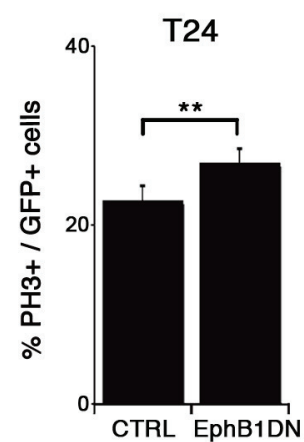

D
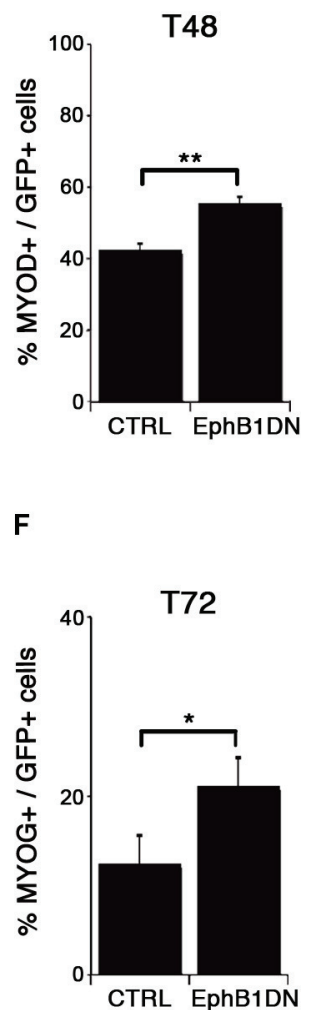

FIGURE 4 | Impairment of EPHB1 function increases proliferation and myogenic differentiation. (A-F) Overexpression of dominant negative EPHB1 (EphB1DN) using retroviruses in C2C12 cells during proliferation at $\mathrm{T}=24 \mathrm{~h}(\mathbf{A}, \mathbf{B}), \mathrm{T}=48 \mathrm{~h}$ (C,D), and during differentiation at $\mathrm{T}=72 \mathrm{~h}(\mathbf{E}, \mathbf{F})$. For each time point, immunostaining and the corresponding quantifications are shown. Control corresponds to infection by a GFP-expressing empty vector. Nuclei are labeled with DAPI (blue). Cell percentages represent the proportion of transduced cells (GFP+) that co-express PH3 (B), MYOD (D), or MYOG (F). $p$-value ${ }^{*} p<0.05$ and ${ }^{* *} p<0.01$. Minimum number of infected cells was 250, for each marker analyzed. Scale bars, $25 \mu \mathrm{m}$.

(Figures 6F,G). These results demonstrate that overexpression of Zfp $354 c$ resulted in a reduction of self-renewal capacity of the satellite cells.

Overexpression of Zcchc5 in satellite cells, as with $Z f p 354 c$, resulted in a decrease of the PAX7+ population relative to control (Figure 6H). Strikingly, the proportion of MYOD+ satellite cells increased without affecting MYOG-expressing differentiated cells (Figures 6I,J). These results showed that overexpression of Zcchc5 induced decreased self-renewal promoting the proliferation of satellite cells. Our functional data is consistent with a specific requirement of Zcchc5 function during the growth phase where production of MPC is needed.

We next overexpressed the other two BTB-containing zinc finger factors, $Z b t b 4$ and $Z b t b 20$ (Figures 6K-P). Zbtb4 increased 


\section{A}
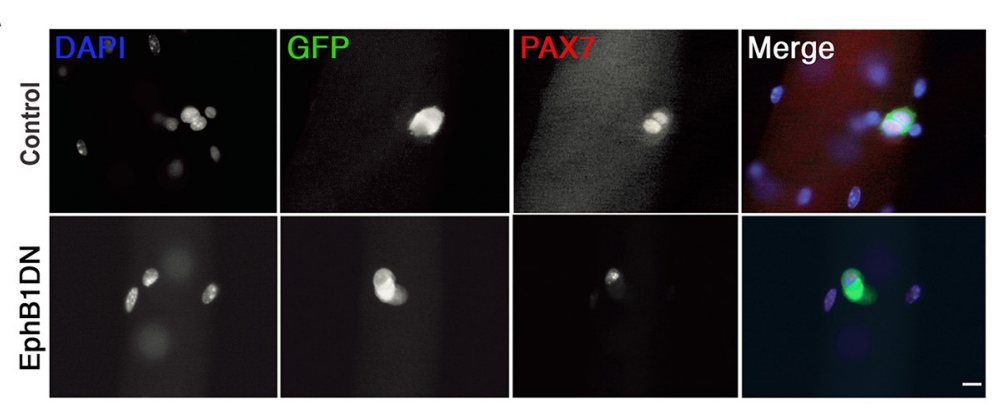

C

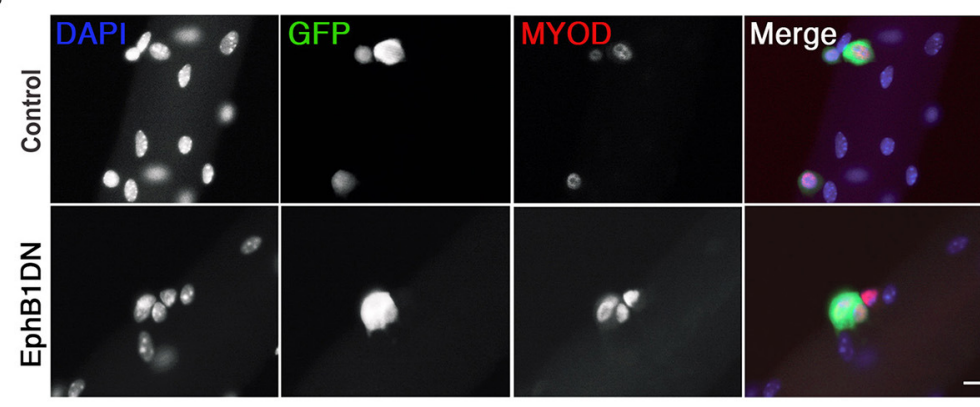

E
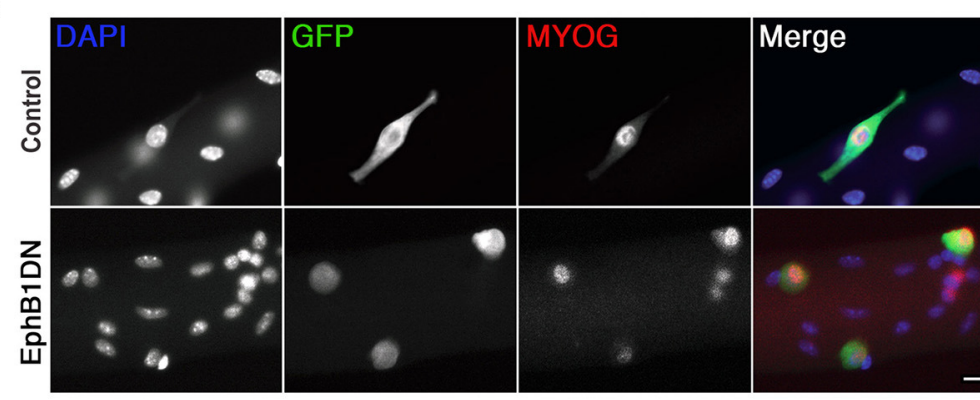

$\mathbf{F}$
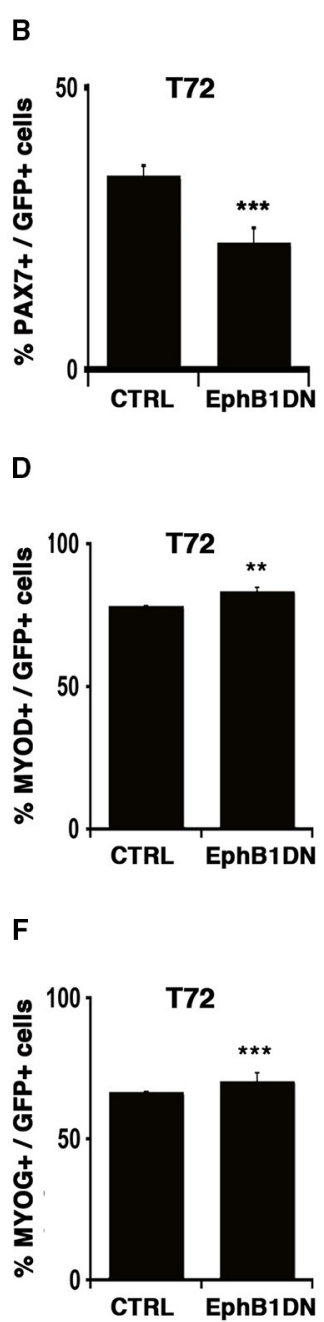

D

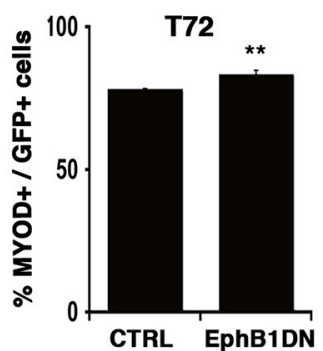

CTRL EphB1DN

CTRL EphB1DN

G

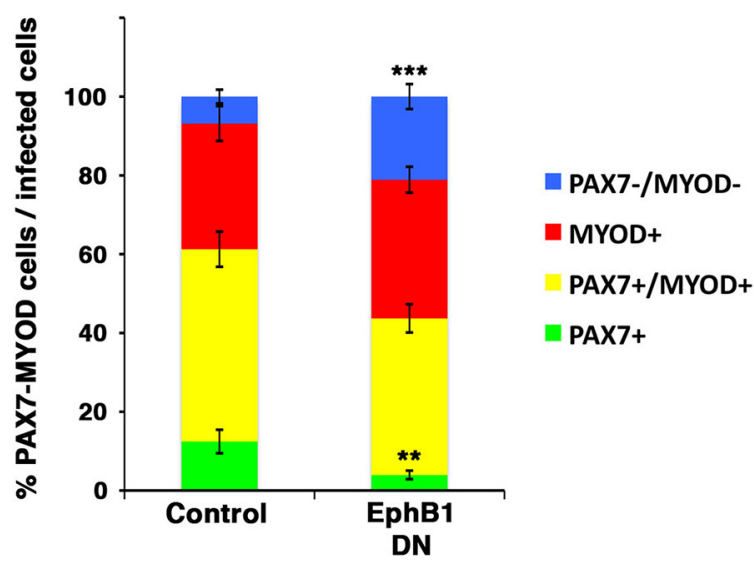

FIGURE 5 | Impairment of EPHB1 function induces satellite cell differentiation. Satellite cells were transduced to overexpress a truncated EPHB1 (EphB1DN) after $24 \mathrm{~h}$ in culture and analyzed $48 \mathrm{~h}$ later (T72). Representative immunofluorescent images are displayed for GFP, DAPI, and PAX7 (A), MYOD (C), and MYOG (Myogenin) (E). Scale bars, $20 \mu \mathrm{m}$. Quantifications are illustrated for quiescence/self-renewal (B), activation (D), and differentiation (F). (G) Quantification of PAX7 and MYOD satellite cells $48 \mathrm{~h}$ after infection with EphB1DN. Control corresponds to infection by a CFP-expressing empty vector. $p$-values: ${ }^{\star *} p<0.01$ and ${ }^{* \star *} p<0.001$. For each marker analyzed, the minimum number of infected satellite cells was 200. 


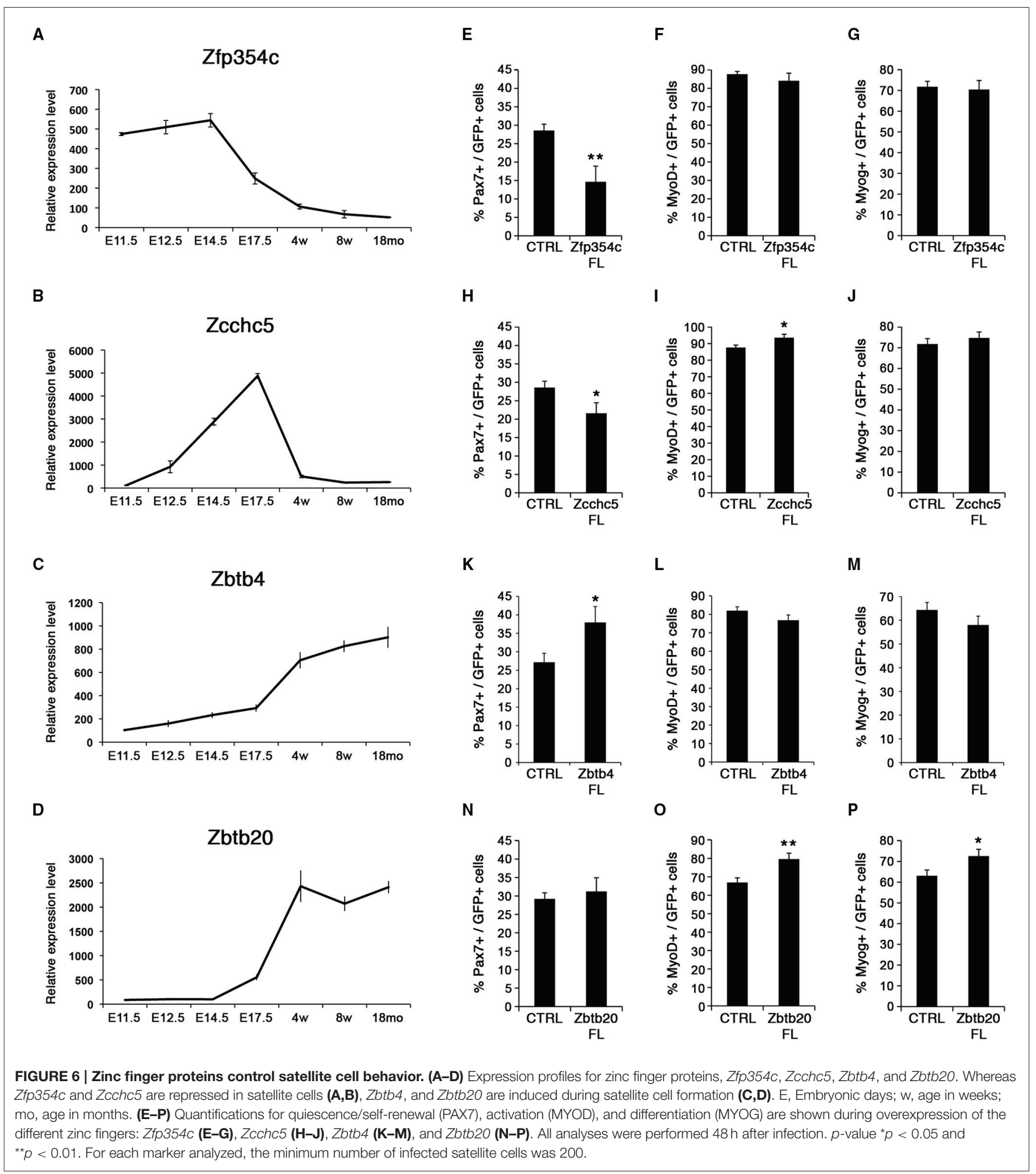

PAX7+ satellite cells (Figure 6K), whereas Zbtb20 promoted myogenic progression by increasing the activated/proliferating (MYOD+; Figure 6O) and differentiating (MYOG+; Figure 6P) populations. These results suggested that these transcriptional repressors might be required for specification/maintenance of the muscle stem cell pool. Strikingly, inhibiting function by expression of ZBTB4 dominant negative constructs, missing the POZ DNA-binding domain, displayed an increase in 
satellite cell differentiation (MYOG+) without affecting the activated/proliferating population (MYOD+) (Figures S8B,C). On the other hand, ZBTB20 could behave with a previously described phenotype in the brain of $Z b t b 20$ transgenic mice (Nielsen et al., 2007), where overexpression of ZBTB20 represses cell fate transitions in newborn pyramidal neurons. Moreover, overexpression of ZBTB20 has been recently described as a prognostic marker by promoting tumor growth of human hepatocellular carcinoma (Kan et al., 2016). Thus, ZBTB20 could be regulating muscle regeneration during satellite cell activation as suggested in Figure S8A.

\section{Hmga2 Must be Repressed for Appropriate Satellite Cell Function}

Hmga2 was highly expressed during early development (Figure 7A), when MPCs expand to populate the future skeletal muscle of the body. As development proceeds, Hmga2 was no longer expressed, and was not detected in the emerging satellite cells prior to birth. Nishino and collaborators have described a similar behavior where Hmga2 is highly expressed in fetal neural stem cells and declining with age (Nishino et al., 2008).

We analyzed the effect of overexpressing Hmga2 in satellite cells (Figures 7B-E). A retroviral construct carrying full-length cDNA including the coding sequence for the basic and acidic region of the protein was generated (Figure $7 \mathbf{B}$ ), and satellite cells transduced using isolated myofiber culture. Hmga2 overexpression led to a strong reduction in the pool of satellite cells expressing PAX7 (Figures 7C,D), with an increase on the activated/proliferating MYOD+ muscle stem cells (Figure 7E); data consistent with the work from $\mathrm{Li}$ and colleagues describing HMGA2 as a regulator of myoblast proliferation by direct interaction with the RNA-binding protein IGF2BP2 (Li et al., 2012).

\section{DISCUSSION}

PAX3 and PAX7 are key upstream regulators of skeletal myogenesis (Relaix et al., 2005; Buckingham and Relaix, 2015). Postnatally, while PAX7 labels all satellite cells (Seale et al., 2000), PAX3 is maintained in a subset of these adult muscle stem cells (Relaix et al., 2006). A complex balance between extrinsic cues and intrinsic regulatory mechanisms is needed to tightly control satellite cell determination and function. For example, defects in satellite cell regulation or changes in their niche, such as during postnatal growth or in degenerative conditions and aging, can impair muscle regeneration with possible fatal consequences (Dumont et al., 2015). Hence, identifying and manipulating muscle progenitor stem cells, and understanding the mechanisms underlying cell fate decision and self-renewal (Relaix, 2006; Boutet et al., 2007) are essential for development of stem cell-based therapeutic strategies.

We have developed a FACs-based chronological transcriptome profile of myogenic stem cells, sampled from embryonic and fetal progenitors, to postnatal, adult, and aging satellite cells. This provides a comprehensive description of gene expression changes throughout life of muscle stem cells and identifies two important transition events, which delimit three developmental periods of muscle stem cells with specific molecular signatures: (1) embryonic, (2) fetal to early proliferating postnatal progenitors, and (3) quiescent adult muscle stem cells (Buckingham and Relaix, 2007; Braun and Gautel, 2011). The intersection between specifically expressed genes and functional pathways defines a molecular signature unique to each developmental period. As such, our study is instrumental for a better understanding of both myogenesis and the establishment and maintenance of quiescent adult stem cells.

The dynamics of our transcriptional profiling reveal that cellular processes characterizing muscle stem cells, including transition from the fetal lineage to postnatal stem cells, establishment of quiescence and formation of a functional niche, are defined molecularly in a more progressive manner, highlighting that establishment of the satellite cell lineage is more gradual than previously recognized. For example, cell division processes (i.e., cyclins such as Ccne1/2 or cyclin-dependent kinases such as $C d k 1$ ) were gradually down-regulated throughout the second transition, corresponding to the entry into satellite cell quiescence and consistent with analysis of fetal progenitor cell proliferation (Picard and Marcelle, 2013). At the same time, known satellite cell markers such as Sdc4 (Syndecan 4), Itga7 (Integrin Alpha-7) or Cav1 (Caveolin 1) were progressively upregulated (Cornelison, 2001; Gnocchi et al., 2009).

From this large-scale myogenesis transcriptome, we functionally characterized a set of genes to provide novel intrinsic factors that regulate satellite cell behavior (Figure 8A).

\section{Eph/Ephrin Pathway and Myogenesis}

EPHB1 is not only involved in motility and guidance in skeletal muscle cells as previously shown (Stark et al., 2011), but also acts as a novel regulator of myogenesis. Our findings point to a function during self-renewal of satellite cells, since a dominant negative form of EPHB1 led to increased proliferation and differentiation in $\mathrm{C} 2 \mathrm{C} 12$ myogenic cells and satellite cells in the myofiber experimental model. The increase in cell differentiation is achieved at the expense of self-renewal of the satellite cell population (Figure 8B). Identifying the molecular regulators of satellite cell renewal is important since it was recently shown that targeted depletion of the satellite cell pool leads to complete impairment of muscle regeneration following injury (reviewed in Relaix and Zammit, 2012).

Eph/ephrin signaling takes place via direct cell-cell interaction; either as trans or cis signaling (Arvanitis and Davy, 2008; Pitulescu and Adams, 2010). This interaction could take place with the muscle fiber, between satellite cells, or via interactions with other cell types in the microenvironment (i.e., macrophages and/or microvascular cells). The satellite cell population is heterogeneous, with specific markers labeling subpopulations of the satellite cell pool and different myogenic behaviors in vivo or ex vivo (Relaix et al., 2006; Kuang et al., 2007; Rudnicki et al., 2008; Ono et al., 2010; Rocheteau et al., 2012). Whether arising through lineage or stochastic events, more "stem" satellite cells likely correspond to independently identified label-retaining satellite cells during growth and after injury (Shinin et al., 2006; Rocheteau et al., 2012; Chakkalakal 
A

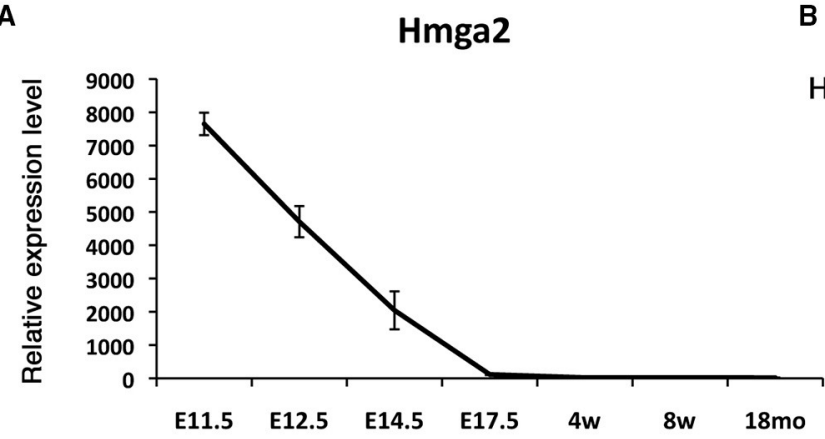

C

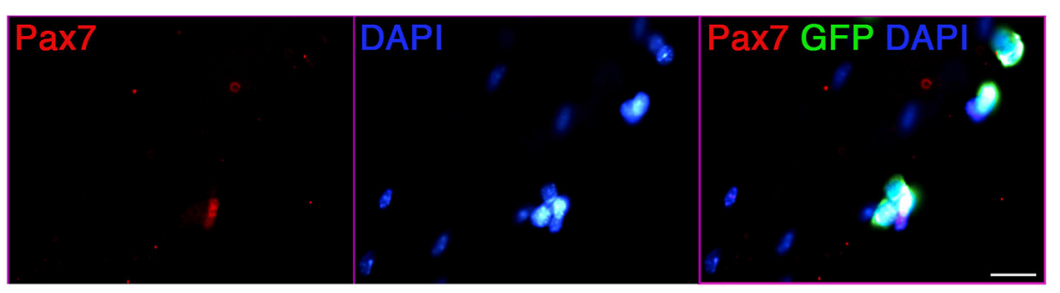

B

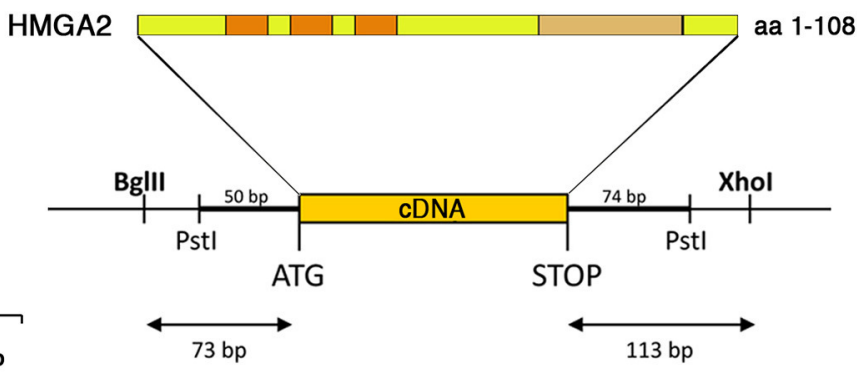

D
TA hook (basic) C C-terminal region (acidic)
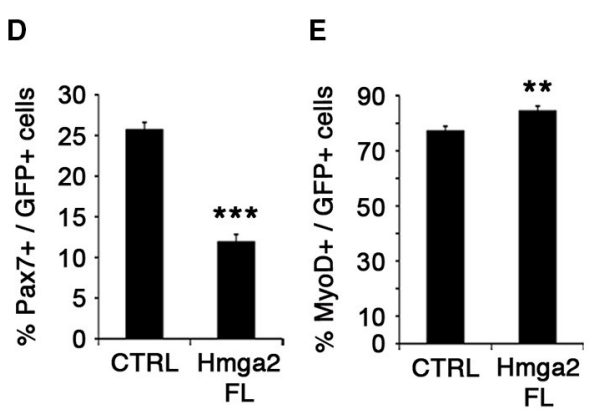

FIGURE 7 | HMGA2 reduces the pool of satellite cells. (A) Expression profile of Hmga2 during development. E, Embryonic days; w, age in weeks; mo, age in months. (B) Protein structure of the non-histone, DNA-binding chromatin HMGA2 factor containing three DNA-binding sites (AT hook motifs) and the basic terminal region, which can bind various proteins. (C) Representative image for the co-immunofluorescence of GFP (green) and PAX7 (red) with DAPI counterstain (blue). Quantification corresponds to the analysis of quiescence (D) and activation (E) of the satellite cells. Forty eight hours after infection, retroviral-mediated overexpression of HMGA2 caused a reduction in the population of PAX7+ cells (D) and an increase MYOD+ cell population (E). $p$-value ${ }^{* *} p<0.01$ and ${ }^{* * *} p<0.001$. For each marker analyzed, the minimum number of infected satellite cells was 500 . Scale bar, $20 \mu \mathrm{m}$.

et al., 2014), or displaying different rates of cell division (Ono et al., 2012). Interestingly, satellite cells can asymmetrically divide and it will be of interest to evaluate if interaction between fibers and/or the satellite cells via the Eph/ephrin signaling plays a role in these cell fate decisions. Finally, our results are consistent with the work from Chumley and colleagues, showing that proliferative neuronal progenitor cells increase in EphB1 mutant mice (Chumley et al., 2007), thereby demonstrating an important role of EPHB1 in maintenance of neuronal progenitors in the quiescent state.

Eph/ephrin signaling has also been shown to play a role in regulating other stem cell niches, for instance in the dental (Stokowski et al., 2007) or osteochondral (Arthur et al., 2011) system. Using an ephrin "stripe" assay revealed that satellite cells respond to a subset of ephrins with repulsive behavior in vitro (Stark et al., 2011). Our finding that EPHB1 is also regulating myogenesis suggests that this guidance signaling might impact multiple aspects of muscle regeneration, including escape from the niche, directed migration to sites of injury, cellcell interactions among satellite cell progeny, and differentiation and patterning of regenerated muscle.

\section{Identification of Novel Zinc Finger Proteins Regulating Myogenesis}

We identified a set of zinc finger containing proteins with a dynamic expression profile during myogenesis. We have shown that overexpression of $Z f p 354 c$ decreased self-renewal of satellite cells (summarized in Figure 8). In the skeletal system, the highest $Z f p 354 c$ expression is in proliferating bone cells compared to mature and differentiated chondrocytes. Interestingly, ZFP354C is induced as an early response to BMP-7 (Jheon et al., 2001). It has been shown that overexpression of $Z f p 354 c$ affects osteoblast differentiation, a lineage that is also regulated by BMP signaling (Jheon et al., 2001). Moreover, overexpression of this gene results in a decrease in osteogenic differentiation by suppressing BMP-7 induced alkaline phosphatase activity, an early marker of osteogenesis (Jheon et al., 2003). Furthermore, BMP signaling prevents myogenic differentiation of satellite cells, and is also involved in regulation of satellite cells during proliferation or differentiation (Friedrichs et al., 2011; Ono et al., 2011). In essence, there is strong evidence of a functional interaction between ZFP354C and BMP7, though the precise relationship between the two proteins is not fully understood (Jheon et al., 2002). Future studies will be necessary to evaluate whether a functional interaction between ZFP354C and BMP7 regulates myogenesis and, in general, to identify the downstream gene regulatory networks for all four zinc finger proteins presented here, ZFP354C, ZCCHC5, ZBTB4, and ZBTB20, which are able to strongly repress transcription of target genes. These zinc fingers, thus, could be used as potentially powerful tools for regulation of muscle stem cell function. 
DEVELOPMENT POSTNATAL GROWTH HOMEOSTASIS / REGENERATION

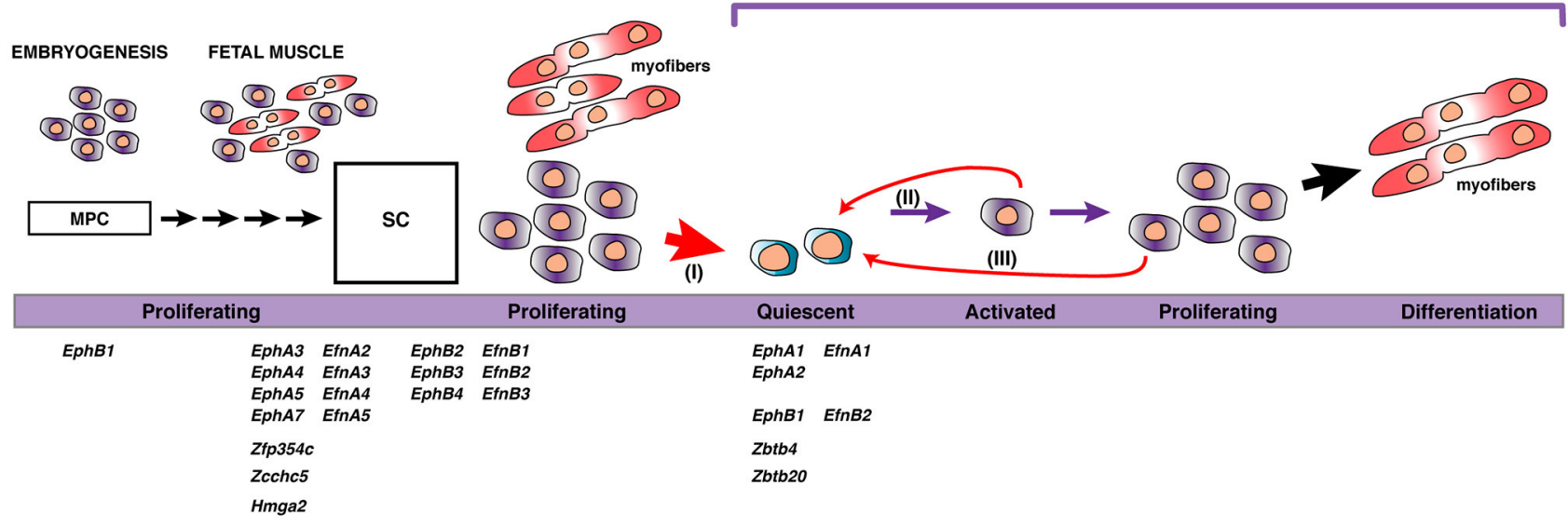

B

DEVELOPMENT

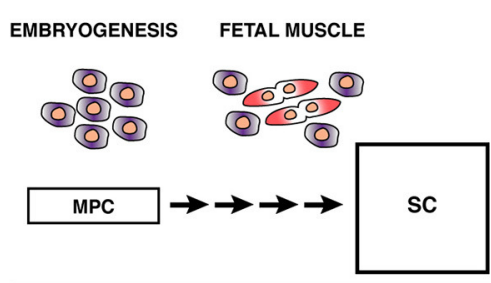

Proliferating

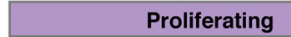

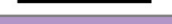

POSTNATAL GROWTH

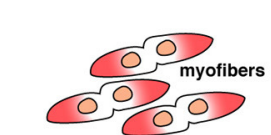

HOMEOSTASIS / REGENERATION

Proliferating
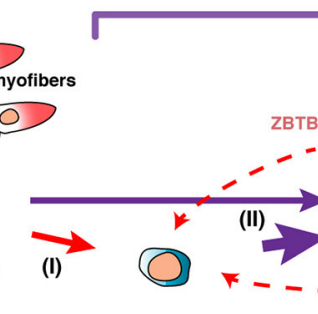

HOMEOSTASIS/REGENERATION

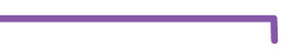

FIGURE 8 | A model for skeletal muscle stem cell behavior during myogenesis. (A) During development, embryonic and fetal progenitors are highly proliferative, augmenting the pool of MPC that will differentiate and fuse to form myofibers. As development proceeds, some of these MPCs become satellite cells (SC), the postnatal muscle stem cells. During the perinatal transition, many of these SCs will contribute to the maturation of myofibers, with a pool of stem cells maintained within their natural niche, underneath the basal lamina surrounding the myofiber. Satellite cells become quiescent by 3 weeks after birth (I). However, in response to injury or disruption of the basal lamina, SCs become activated (II), start proliferating, and differentiate to fuse with each other or to existing myofibers for repair. Some of these will self-renew to replenish the pool of quiescent stem cells (III). The putative role and expression of the set of transcripts that we identified in this work is displayed. In addition, we show that manipulating their expression or function can lead to impaired myogenesis (B), either via reduction of the pool of stem cells by promoting proliferation or cell fate determination, or through inducing precocious myogenic differentiation.

\section{HMGA2 Function and Its Role in Myogenesis and Satellite Cell Fate Decision}

HMGA2 is a co-regulator of chromatin structure and pluripotency in stem cells (Pfannkuche et al., 2009). The role of HMGA2 in myoblast proliferation has been previously described in neonatal and regenerating muscle (Li et al., 2012). Hmga2 is sharply induced during satellite cell activation. We found that Hmga2 is highly expressed during early muscle development and progressively down-regulated in the fetal stages, while it is not expressed during growth or aging (Figure 7A). It has been shown that Hmga2 knockout mice are smaller and show defects in postnatal skeletal muscle (Zhou et al., 1995; Li et al., 2012). In addition, HMGA2/IGF2BP2 has been shown to be critical for myoblast proliferation and early myogenesis, but should be down-regulated in order for myoblasts to differentiate into multinucleated skeletal muscle. Indeed, when satellite cells are activated and entering cell cycle, HMGA2 is up-regulated and activates the expression of IGF2BP2 (Li et al., 2012). Our transcriptome analysis shows that $\operatorname{Igf} 2 b p 2$ behaves similarly to Hmga2 before birth, but in contrast to Hmga2, Igfbp2 is induced in adult stem cells, including aged satellite cells (data not shown). This suggests that IGF2BP2 could be functionally independent of HMGA2 in adult and aged satellite cells. 
In conclusion, understanding the molecular signals that control and regulate the muscle stem cell population is essential to identify new therapeutic strategies for muscle diseases. Here we provide a set of potential new regulators of myogenesis that improves the understanding and knowledge of the intrinsic factors controlling muscle stem cell acquisition, establishment, maintenance and function in the adult, and could be targeted to modify the regenerative capacity of endogenous skeletal muscle stem cells.

\section{AUTHOR CONTRIBUTIONS}

SAM, AR, and JM designed and performed experiments, and analyzed data. SAM wrote the manuscript. AD analyzed bioinformatic data. DM, FA, and TC performed experiments. PZ designed experiments. FR oversaw the entire project, designed experiments, analyzed data and wrote the manuscript. All authors read and approved the final manuscript.

\section{ACKNOWLEDGMENTS}

We thank Jonathan A. Epstein for the $\mathrm{Pax} 3^{\mathrm{Cre} /+}$ mice. We thank Bernadette Drayton, Bruno Cadot, and Petra Gimpel for their input and technical assistance; Ana Cumano for her advice in FACS-sorting experiments and Olivier Poch and Julie Thompson for discussion about gene expression analysis. We thank Catherine Blanc and Bénédicte Hoareau (Flow Cytometry Core CyPS, Pierre and Marie Curie University) for their assistance. We also wish to acknowledge Serban Morosan and the animal care facility (Centre d'Expérimentation Fonctionnelle, School of Medicine Pierre et Marie Curie).

\section{REFERENCES}

Abou-Khalil, R., Le Grand, F., Pallafacchina, G., Valable, S., Authier, F.-J., Rudnicki, M. A., et al. (2009). Autocrine and paracrine angiopoietin 1/Tie-2 signaling promotes muscle satellite cell self-renewal. Cell Stem Cell 5, 298-309. doi: 10.1016/j.stem.2009.06.001

Amthor, H., Christ, B., Weil, M., and Patel, K. (1998). The importance of timing differentiation during limb muscle development. Curr. Biol. 8, 642-652. doi: 10.1016/S0960-9822(98)70251-9

Arthur, A., Zannettino, A., Panagopoulos, R., Koblar, S. A., Sims, N. A., Stylianou, C., et al. (2011). EphB/ephrin-B interactions mediate human MSC attachment, migration and osteochondral differentiation. Bone 48, 533-542. doi: 10.1016/j.bone.2010.10.180

Arvanitis, D., and Davy, A. (2008). Eph/ephrin signaling: networks. Genes Dev. 22, 416-429. doi: 10.1101/gad.1630408

Ashar, H. R., Chouinard, R. A. Jr., Dokur, M., and Chada, K. (2010). In vivo modulation of HMGA2 expression. Biochim. Biophys. Acta 1799, 55-61. doi: 10.1016/j.bbagrm.2009.11.013

Bismuth, K., and Relaix, F. (2010). Genetic regulation of skeletal muscle development. Exp. Cell Res. 316, 3081-3086. doi: 10.1016/j.yexcr.2010.08.018

Boldrin, L., Neal, A., Zammit, P. S., Muntoni, F., and Morgan, JE. (2012). Donor satellite cell engraftment is significantlyaugmented when the host niche is preserved and endogenous satellite cells are incapacitated. Stem Cells 30, 1971-1984. doi: 10.1002/stem.1158

Boutet, S. C., Disatnik, M.-H., Chan, L. S., Iori, K., and Rando, TA. (2007). Regulation of Pax3 by proteasomal degradation of monoubiquitinated
SAM was recipient of a postdoctoral fellowship from the Basque Community (BF106.177). This work was supported by funding to FR from INSERM Avenir Program, Association Française contre les Myopathies (AFM) via TRANSLAMUSCLE (PROJECT 19507), Association Institut de Myologie (AIM), Labex REVIVE (ANR-10-LABX-73), the European Union Sixth and Seventh Framework Program in the project MYORES and ENDOSTEM (Grant \# 241440), Fondation pour la Recherche Médicale (FRM; Grant FDT20130928236), Ligue Nationale contre le Cancer, Agence Nationale pour la Recherche (ANR) grant Epimuscle (ANR 11 BSV2 017 02), RHU CARMMA (ANR-15-RHUS-0003), BMP-biomass (ANR-12BSV1-0038- 04), Satnet (ANR-15-CE13-0011-01) and bonemuscle-repair (ANR-13-BSV1-0011-02), Decrypthon research program. This work was also funded by the German Research Foundation (DFG; Grant GK1631), French-German University (UFA-DFH; Grant CDFA-06-11) and the AFM as part of the MyoGrad International Research Training Group for Myology. PSZ wishes to acknowledge support from the Association Française contre les Myopathies grant 16050. The lab of PZ is also supported by The Muscular Dystrophy Campaign, the Medical Research Council, FSH Society and BIODESIGN (262948-2) through EU FP7. The funders had no role in study design, data collection and analysis, decision to publish, or preparation of the manuscript. The authors declare no competing financial interests.

\section{SUPPLEMENTARY MATERIAL}

The Supplementary Material for this article can be found online at: http://journal.frontiersin.org/article/10.3389/fcell. 2016.00058 protein in skeletal muscle progenitors. Cell 130, 349-362. doi: 10.1016/j.cell.2007.05.044

Brack, A. S., Conboy, I. M., Conboy, M. J., Shen, J., and Rando, TA. (2008). A temporal switch from notch to Wnt signaling in muscle stem cells is necessary for normal adult myogenesis. Cell Stem Cell 2, 50-59. doi: 10.1016/j.stem.2007.10.006

Brack, A. S., and Rando, TA. (2012). Tissue-specific stem cells: lessons from the skeletal muscle satellite cell. Cell Stem Cell 10, 504-514. doi: 10.1016/j.stem.2012.04.001

Brandt, J., Veith, A. M., and Volff, J. N. (2005). A family of neofunctionalized Ty3/gypsy retrotransposon genes in mammalian genomes. Cytogenet. Genome Res. 110, 307-317. doi: 10.1159/000084963

Braun, T., and Gautel, M. (2011). Transcriptional mechanisms regulating skeletal muscle differentiation, growth and homeostasis. Nat. Rev. Mol. Cell Biol. 12, 349-361. doi: 10.1038/nrm3118

Brohl, D., Vasyutina, E., Czajkowski, M. T., Griger, J., Rassek, C., Rahn, H. P., et al. (2012). Colonization of the satellite cell niche by skeletal muscle progenitor cells depends on notch signals. Dev. Cell 23, 469-481. doi: 10.1016/j.devcel.2012.07.014

Buckingham, M., and Relaix, F. (2007). The role of Pax genes in the development of tissues and organs: Pax3 and Pax7 regulate muscle progenitor cell functions. Annu. Rev. Cell Dev. Biol. 23, 645-673. doi: 10.1146/annurev.cellbio.23.090506.123438

Buckingham, M., and Relaix, F. (2015). PAX3 and PAX7 as upstream regulators of myogenesis. Semin. Cell Dev. Biol. 44, 115-125. doi: 10.1016/j.semcdb.2015. 09.017 
Calhabeu, F., Hayashi, S., Morgan, J. E., Relaix, F., and Zammit, P. S. (2013). Alveolar rhabdomyosarcoma-associated proteins PAX3/FOXO1A and PAX7/FOXO1A suppress the transcriptional activity of MyoD-target genes in muscle stem cells. Oncogene 32, 651-662. doi: 10.1038/onc.2012.73

Cao, D., Ma, X., Cai, J., Luan, J., Liu, A. J., Yang, R., et al. (2016). ZBTB20 is required for anterior pituitary development and lactotrope specification. Nat. Commun. 7:11121. doi: $10.1038 /$ ncomms 11121

Chakkalakal, J. V., Christensen, J., Xiang, W., Tierney, M. T., Boscolo, F. S., Sacco, A., et al. (2014). Early forming label-retaining muscle stem cells require p27kip1 for maintenance of the primitive state. Development 141, 1649-1659. doi: 10.1242/dev.100842

Chumley, M. J., Catchpole, T., Silvany, R. E., Kernie, S. G., and Henkemeyer, M. (2007). EphB receptors regulate stem/progenitor cell proliferation, migration, and polarity during hippocampal neurogenesis. J. Neurosci. 27, 13481-13490. doi: 10.1523/JNEUROSCI.4158-07.2007

Conboy, I. M., and Rando, T. A. (2012). Heterochronic parabiosis for the study of the effects of aging on stem cells and their niches. Cell Cycle 11, 2260-2267. doi: $10.4161 /$ cc. 20437

Cornelison, D. (2001). Syndecan-3 and syndecan-4 specifically mark skeletal muscle satellite cells and are implicated in satellite cell maintenance and muscle regeneration. Dev. Biol. 239, 79-94. doi: 10.1006/dbio.2001.0416

Diez-Roux, G., Banfi, S., Sultan, M., Geffers, L., Anand, S., Rozado, D., et al. (2011). A high-resolution anatomical atlas of the transcriptome in the mouse embryo. PLoS Biol. 9:e1000582. doi: 10.1371/journal.pbio.1000582

Dumont, N. A., Wang, Y. X., and Rudnicki, M. A. (2015). Intrinsic and extrinsic mechanisms regulating satellite cell function. Development 142, 1572-1581. doi: $10.1242 /$ dev.114223

Engleka, K. A., Gitler, A. D., Zhang, M., Zhou, D. D., High, F. A., and Epstein, J. A. (2005). Insertion of Cre into the Pax3 locus creates a new allele of Splotch and identifies unexpected Pax3 derivatives. Dev. Biol. 280, 396-406. doi: 10.1016/j.ydbio.2005.02.002

Epstein, D. J., Vogan, K. J., Trasler, D. G., and Gros, P. (1993). A mutation within intron 3 of the Pax-3 gene produces aberrantly spliced MRNA transcripts in the splotch (Sp) mouse mutant. Genesis 90, 532-536. doi: 10.1073/pnas.90.2.532

Filion, G. J. P., Zhenilo, S., Salozhin, S., Yamada, D., Prokhortchouk, E., and Defossez, P. A. (2006). A family of human zinc finger proteins that bind methylated DNA and repress transcription. Mol. Cell. Biol. 26, 169-181. doi: 10.1128/MCB.26.1.169-181.2006

Friedrichs, M., Wirsdoerfer, F., Flohe, S. B., Schneider, S., Wuelling, M., and Vortkamp, A. (2011). BMP signaling balances proliferation and differentiation of muscle satellite cell descendants. BMC Cell Biol. 12:26. doi: 10.1186/14712121-12-26

Ganss, B., and Jheon, A. (2004). Zinc finger transcription factors in skeletal development. Crit. Rev. Oral Biol. Med. 15, 282-297. doi: $10.1177 / 154411130401500504$

Genander, M., and Frisen, J. (2010). Ephrins and Eph receptors in stem cells and cancer. Curr. Opin. Cell Biol. 22, 611-616. doi: 10.1016/j.ceb.2010.08.005

Gnocchi, V. F., White, R. B. Ono, Y., Ellis, J. A., and Zammit, P. S. (2009). Further characterisation of the molecular signature of quiescent and activated mouse muscle satellite cells. PLoS ONE 4:e5205. doi: 10.1371/journal.pone. 0005205

Haldimann, M., Custer, D., Munarini, N., Stirnimann, C., Zürcher, G., Rohrbach, V., et al. (2009). Deregulated ephrin-B2 expression in the mammary gland interferes with the development of both the glandular epithelium and vasculature and promotes metastasis formation. Int. J. Oncol. 35, 525-536. doi: 10.3892/ijo_00000364

Jheon, A., Chen, J., Teo, W., Ganss, B., Sodek, J., and Cheifetz, S. (2002). Temporal and spatial expression of a novel zinc finger transcription factor, AJ18, in developing murine skeletal tissues. J. Histochem. Cytochem. 50, 973-982. doi: 10.1177/002215540205000711

Jheon, A. H., Ganss, B., Cheifetz, S., and Sodek, J. (2001). Characterization of a novel $\mathrm{KRAB} / \mathrm{C} 2 \mathrm{H} 2$ zinc finger transcription factor involved in bone development. J. Biol. Chem. 276, 18282-18289. doi: 10.1074/jbc.M010885200

Jheon, A. H., Suzuki, N., Nishiyama, T., Cheifetz, S., Sodek, J., and Ganss, B. (2003). Characterization of the $5^{\prime}$-flanking region of the rat AJ18 gene. Gene 310, 203-213. doi: 10.1016/S0378-1119(03)00553-5

Juan, A. H., Derfoul, A., Feng, X., Ryall, J. G., Dell'Orso, S., Pasut, A., et al. (2011). Polycomb EZH2 controls self-renewal and safeguards the transcriptional identity of skeletal muscle stem cells. Genes Dev. 25, 789-794. doi: $10.1101 / \operatorname{gad} .2027911$

Kan, H., Huang, Y., Li, X., Liu, D., Chen, J., and Shu, M. (2016). Zinc finger protein ZBTB20 is an independent prognostic marker and promotes tumor growth of human hepatocellular carcinoma by repressing FoxO1. Oncotarget 7, 14336-14349. doi: 10.18632/oncotarget.7425

Kassar-Duchossoy, L., Giacone, E., Gayraud-Morel, B., Jory, A., Gomès, D., and Tajbakhsh, S. (2005). Pax3/Pax7 mark a novel population of primitive myogenic cells during development. Genes Dev. 19, 1426-1431. doi: 10.1101/gad.345505

Kuang, S., Gillespie, M. A., and Rudnicki, M. A. (2008). Niche regulation of muscle satellite cell self-renewal and differentiation. Cell Stem Cell 2, 22-31. doi: 10.1016/j.stem.2007.12.012

Kuang, S., Kuroda, K., Le Grand, F., and Rudnicki, M. A. (2007). Asymmetric selfrenewal and commitment of satellite stem cells in muscle. Cell 129, 999-1010. doi: 10.1016/j.cell.2007.03.044

Lagha, M., Sato, T., Regnault, B., Cumano, A., Zuniga, A., Licht, J., et al. (2010). Transcriptome analyses based on genetic screens for Pax3 myogenic targets in the mouse embryo. BMC Genomics 11:696. doi: 10.1186/1471-2164-11-696

Lepper, C., Conway, S. J., and Fan, C.-M. (2009). Adult satellite cells and embryonic muscle progenitors have distinct genetic requirements. Nature 460, 627-631. doi: 10.1038/nature08209

Li, Y., Yang, D., Bai, Y., Mo, X., Huang, W., Yuan, W., et al. (2008). ZNF418, a novel human $\mathrm{KRAB} / \mathrm{C} 2 \mathrm{H} 2$ zinc finger protein, suppresses MAPK signaling pathway. Mol. Cell. Biochem. 310, 141-151. doi: 10.1007/s11010-007-9674-4

Li, Z., Gilbert, J. A., Zhang, Y., Zhang, M., Qiu, Q., Ramanujan, K., et al. (2012). An HMGA2-IGF2BP2 axis regulates myoblast proliferation and myogenesis. Dev. Cell 23, 1176-1188. doi: 10.1016/j.devcel.2012.10.019

Linker, C., Lesbros, C., Stark, M. R., and Marcelle, C. (2003). Intrinsic signals regulate the initial steps of myogenesis in vertebrates. Development 130, 4797-4807. doi: 10.1242/dev.00688

Liu, L., Cheung, T. H., Charville, G. W., Hurgo, B. M., Leavitt, T., Shih, J., et al. (2013). Chromatin modifications as determinants of muscle stem cell quiescence and chronological aging. Cell Rep. 4, 189-204. doi: 10.1016/j.celrep.2013.05.043

Lupo, A., Cesaro, E., Montano, G., Zurlo, D., Izzo, P., and Costanzo, P. (2013). KRAB-zinc finger proteins: a repressor family displaying multiple biological functions. Curr. Genomics 14, 268-278. doi: 10.2174/13892029113149 990002

Mauro, A. (1961). Satellite cell of skeletal mucle fibres. J. Biophys. Biochem. Cytol. 9, 493-495. doi: 10.1083/jcb.9.2.493

McMahon, D. K., Anderson, P. A., Nassar, R., Bunting, J. B., Saba, Z., Oakeley, A. E., et al. (1994). C2C12 cells: biophysical, biochemical, and immunocytochemical properties. Am. J. Physiol. Cell Physiol. 266, C1795C1802.

Messina, G., and Cossu, G. (2009). The origin of embryonic and fetal myoblasts: a role of Pax3 and Pax7. Genes Dev. 23, 902-905. doi: 10.1101/gad.1797009

Mitchelmore, C. (2002). Characterization of two novel nuclear BTB/POZ domain zinc finger isoforms. Association with Differentiation of Hippocampal Neurons, Cerebellar Granule Cells, and Macroglia. J. Biol. Chem. 277, 7598-7609. doi: 10.1074/jbc.M110023200

Montarras, D., Morgan, J., Collins, C., Relaix, F., Zaffran, S., Cumano, A., et al. (2005). Direct isolation of satellite cells for skeletal muscle regeneration. Science 309, 2064-2067. doi: 10.1126/science.1114758

Moyle, L. A., and Zammit, P. S. (2014). Isolation, culture and immunostaining of skeletal muscle fibres to study myogenic progression in satellite cells. Methods Mol. Biol. 1210, 63-78. doi: 10.1007/978-1-4939-1435-7_6

Murai, K. K., and Pasquale, E. B. (2010). Restraining stem cell niche plasticity: a new talent of Eph receptors. Cell Stem Cell 7, 647-648. doi: 10.1016/j.stem.2010.11.023

Murphy, M., and Kardon, G. (2011). Origin of vertebrate limb muscle: the role of progenitor and myoblast populations. Curr. Top. Dev. Biol. 96, 1-32. doi: 10.1016/B978-0-12-385940-2.00001-2

Muzumdar, M. D., Tasic, B., Miyamichi, K., Li, L., and Luo, L. (2007). A global double-fluorescent Cre reporter mouse. Genesis 45, 593-605. doi: 10.1002/dvg.20335

Nagao, M., Ogata, T., Sawada, Y., and Gotoh, Y. (2016). Zbtb20 promotes astrocytogenesis during neocortical development. Nat. Commun. 7:11102. doi: $10.1038 /$ ncomms 11102 
Nielsen, J. V., Nielsen, F. H., Ismail, R., Noraberg, J., and Jensen, N. A. (2007). Hippocampus-like corticoneurogenesis induced by two isoforms of the BTB-zinc finger gene Zbtb20 in mice. Development 134, 1133-1140. doi: $10.1242 /$ dev.000265

Nishino, J., Kim, I., Chada, K., and Morrison, S. J. (2008). Hmga2 promotes neural stem cell self-renewal in young but not old mice by reducing p16Ink4a and p19Arf expression. Cell 135, 227-239. doi: 10.1016/j.cell.2008.09.017

Oda-Ishii, I., Ishii, Y., and Mikawa, T. (2010). Eph regulates dorsoventral asymmetry of the notochord plate and convergent extension-mediated notochord formation. PLOS ONE 5:e13689. doi: 10.1371/journal.pone.0013689

Okabe, H., Satoh, S., Furukawa, Y., Kato, T., Hasegawa, S., Nakajima, Y., et al. (2003). Involvement of PEG10 in human hepatocellular carcinogenesis through interaction with SIAH1. Cancer Res. 63, 3043-3048.

Olguin, H. C., and Olwin, B. B. (2004). Pax-7 up-regulation inhibits myogenesis and cell cycle progression in satellite cells: a potential mechanism for selfrenewal. Dev. Biol. 275, 375-388. doi: 10.1016/j.ydbio.2004.08.015

Ono, Y., Boldrin, L., Knopp, P., Morgan, J. E., and Zammit, P. S. (2010). Muscle satellite cells are a functionally heterogeneous population in both somite-derived and branchiomeric muscles. Dev. Biol. 337, 29-41. doi: 10.1016/j.ydbio.2009.10.005

Ono, Y., Calhabeu, F., Morgan, J. E., Katagiri, T., Amthor, H., and Zammit, P. S. (2011). BMP signalling permits population expansion by preventing premature myogenic differentiation in muscle satellite cells. Cell Death Differ. 18, 222-234. doi: 10.1038/cdd.2010.95

Ono, Y., Masuda, S., Nam, H. S., Benezra, R., Miyagoe-Suzuki, Y., and Takeda, S. (2012). Slow-dividing satellite cells retain long-term self-renewal ability in adult muscle. J. Cell Sci. 125, 1309-1317. doi: 10.1242/jcs.096198

Palmer, A., and Klein, R. (2003). Multiple roles of ephrins in morphogenesis, neuronal networking, and brain function. Genes Dev. 17, 1429-1450. doi: $10.1101 /$ gad. 1093703

Pasquale, E. B. (2005). Eph receptor signalling casts a wide net on cell behaviour. Nat. Rev. Mol. Cell Biol. 6, 462-475. doi: 10.1038/nrm1662

Pasquale, E. B. (2010). Eph receptors and ephrins in cancer: bidirectional signalling and beyond. Nat. Rev. Cancer 10, 165-180. doi: 10.1038/nrc2806

Pear, W., Miller, J., Xu, L., Pui, J., Soffer, B., Quackenbush, R., et al. (1998). Efficient and rapid induction of a chronic myelogenous leukemia-like myeloproliferative disease in mice receiving P210 bcr/abl-transduced bone marrow. Blood 92, 3780-3792.

Pfannkuche, K., Summer, H., Li, O., Hescheler, J., and Droge, P. (2009). The high mobility group protein HMGA2: a co-regulator of chromatin structure and pluripotency in stem cells $\beta$ Stem Cell Rev. 5, 224-230. doi: 10.1007/s12015-0099078-9

Picard, C. A., and Marcelle, C. (2013). Two distinct muscle progenitor populations coexist throughout amniote development. Dev. Biol. 373, 141-148. doi: 10.1016/j.ydbio.2012.10.018

Pitulescu, M. E., and Adams, R. H. (2010). Eph/ephrin molecules-a hub for signaling and endocytosis. Genes Dev. 24, 2480-2492. doi: 10.1101/gad.1973910

Relaix, F. (2006). Skeletal muscle progenitor cells: from embryo to adult. Cell. Mol. Life Sci. 63, 1221-1225. doi: 10.1007/s00018-006-6015-9

Relaix, F., and Marcelle, C. (2009). Muscle stem cells. Curr. Opin. Cell Biol. 21, 748-753. doi: 10.1016/j.ceb.2009.10.002

Relaix, F., Montarras, D., Zaffran, S., Gayraud-Morel, B., Rocancourt, D., Tajbakhsh, S., et al. (2006). Pax3 and Pax7 have distinct and overlapping functions in adult muscle progenitor cells. J. Cell Biol. 172, 91-102. doi: $10.1083 /$ jcb.200508044

Relaix, F., Rocancourt, D., Mansouri, A., and Buckingham, M. (2005). A Pax3/Pax7-dependent population of skeletal muscle progenitor cells. Nature 435, 948-953. doi: 10.1038/nature03594

Relaix, F., and Zammit, P. S. (2012). Satellite cells are essential for skeletal muscle regeneration: the cell on the edge returns centre stage. Development 139, 2845-2856. doi: 10.1242/dev.069088

Rocheteau, P., Gayraud-Morel, B., Siegl-Cachedenier, I., Blasco, M. A., and Tajbakhsh, S. (2012). A subpopulation of adult skeletal muscle stem cells retains all template DNA strands after cell division. Cell 148, 112-125. doi: 10.1016/j.cell.2011.11.049

Rudnicki, M. A., Le Grand, F., McKinnell, I., and Kuang, S. (2008). The molecular regulation of muscle stem cell function. Cold Spring Harb. Symp. Quant. Biol. 73, 323-331. doi: 10.1101/sqb.2008.73.064
Sambasivan, R., Kuratani, S., and Tajbakhsh, S. (2011). An eye on the head: the development and evolution of craniofacial muscles. Development 138, 2401-2415. doi: 10.1242/dev.040972

Sartori, R., Schirwis, E., Blaauw, B., Bortolanza, S., Zhao, J., Enzo, E., et al. (2013). BMP signaling controls muscle mass. Nat. Genet. 45, 1309-1318. doi: $10.1038 /$ ng.2772

Seale, P., Sabourin, L. A., Girgis-Gabardo, A., Mansouri, A., Gruss, P., and Rudnicki, M. A. (2000). Pax7 is required for the specification of myogenic satellite cells. Cell 102, 777-786. doi: 10.1016/S0092-8674(00)00066-0

Shefer, G., Van de Mark, D. P., Richardson, J. B., and Yablonka-Reuveni, Z. (2006). Satellite-cell pool size does matter: defining the myogenic potency of aging skeletal muscle. Dev. Biol. 294, 50-66. doi: 10.1016/j.ydbio.2006.02.022

Shinin, V., Gayraud-Morel, B., Gomes, D., and Tajbakhsh, S. (2006). Asymmetric division and cosegregation of template DNA strands in adult muscle satellite cells. Nat. Cell Biol. 8, 677-687. doi: 10.1038/ncb1425

Singla, N., Goldgur, Y., Xu, K., Paavilainen, S., Nikolov, D. B., and Himanen, J. P. (2010). Crystal structure of the ligand-binding domain of the promiscuous EphA4 receptor reveals two distinct conformations. Biochem. Biophys. Res. Commun. 399, 555-559. doi: 10.1016/j.bbrc.2010.07.109

Sinha, M., Jang, Y. C., Oh, J., Khong, D., Wu, E. Y., Manohar, R., et al. (2014). Restoring systemic GDF11 levels reverses age-related dysfunction in mouse skeletal muscle. Science 344, 649-652. doi: 10.1126/science.1251152

Sousa-Victor, P., Gutarra, S., García-Prat, L., Rodriguez-Ubreva, J., Ortet, L., RuizBonilla, V., et al. (2014). Geriatric muscle stem cells switch reversible quiescence into senescence. Nature 506, 316-321. doi: 10.1038/nature13013

Sreevalsan, S., and Safe, S. (2013). Reactive oxygen species and colorectal cancer. Curr. Colorectal Cancer Rep. 9, 350-357. doi: 10.1007/s11888-013-0190-5

Stark, D. A., Coffey, N. J., Pancoast, H. R., Arnold, L. L., Walker, J. P., Vallée, J., et al. (2015). Ephrin-A3 promotes and maintains slow muscle fiber identity during postnatal development and reinnervation. J. Cell Biol. 211, 1077-1091. doi: $10.1083 /$ jcb.201502036

Stark, D. A., Karvas, R. M., Siegel, A. L., and Cornelison, D. D. (2011). Eph/ephrin interactions modulate muscle satellite cell motility and patterning. Development 138, 5279-5289. doi: 10.1242/dev.068411

Stokowski, A., Shi, S., Sun, T., Bartold, P. M., Koblar, S. A., and Gronthos, S. (2007). EphB/ephrin-B interaction mediates adult stem cell attachment, spreading, and migration: implications for dental tissue repair. Stem Cells 25, 156-164. doi: 10.1634/stemcells.2006-0373

Stoller, J. Z., Degenhardt, K. R., Huang, L., Zhou, D. D., Lu, M. M., and Epstein, J. A. (2008). Cre reporter mouse expressing a nuclear localized fusion of GFP and $\beta$-galactosidase reveals new derivatives of Pax3-expressing precursors. Genesis 46, 200-204. doi: $10.1002 /$ dvg.20384

Sutherland, A. P. R., Zhang, H., Zhang, Y., Michaud, M., Xie, Z., Patti, M. E., et al. (2009). Zinc finger protein zbtb20 is essential for postnatal survival and glucose homeostasis. Mol. Cell. Biol. 29, 2804-2815. doi: 10.1128/MCB.01667-08

Tajbakhsh, S. (2009). Skeletal muscle stem cells in developmental versus regenerative myogenesis. J. Intern. Med. 266, 372-389. doi: 10.1111/j.13652796.2009.02158.x

Tajbakhsh, S., and Buckingham, M. (2000). The birth of muscle progenitor cells in the mouse: spatiotemporal considerations. Curr. Top. Dev. Biol. 48, 225-268. doi: 10.1016/S0070-2153(08)60758-9

Thanos, D., and Maniatis, T. (1992). The high mobility group protein HMG I(Y) is required for NF-kB-dependent virus induction of the human IFN- $\beta$ gene. Cell 71, 777-789. doi: 10.1016/0092-8674(92)90554-P

Tian, C. Y., Zhang, L. Q., and He, F. C. (2006). Progress in the study of KRAB zinc finger protein. Yi Chuan 28, 1451-1456. doi: 10.1360/yc-006-1451

Urrutia, R. (2003). KRAB-containing zinc-finger repressor proteins. Genome Biol. 4:231. doi: 10.1186/gb-2003-4-10-231

Vindis, C., Cerretti, D. P., Daniel, T. O., and Huynh-Do, U. (2003). EphB1 recruits c-Src and p52Shc to activate MAPK/ERK and promote chemotaxis. J. Cell Biol. 162, 661-671. doi: 10.1083/jcb.200302073

Vindis, C., Teli, T., Cerretti, D. P., Turner, C. E., and Huynh-Do, U. (2004). EphB1-mediated cell migration requires the phosphorylation of paxillin at Tyr-31/Tyr-118. J. Biol. Chem. 279, 27965-27970. doi: 10.1074/jbc.M401295200

Wang, H., Noulet, F., Edom-Vovard, F., Le Grand, F., and Duprez, D. (2010). Bmp signaling at the tips of skeletal muscles regulates the number of fetal muscle progenitors and satellite cells during development. Dev. Cell 18, 643-654. doi: 10.1016/j.devcel.2010.02.008 
Wang, Y. X., and Rudnicki, M. A. (2011). Satellite cells, the engines of muscle repair. Nat. Rev. Mol. Cell Biol. 13, 127-133. doi: 10.1038/nrm3265

Watson, R. P., Tekki-Kessaris, N., and Boulter, C. A. (2000). Characterisation, chromosomal localisation and expression of the mouse Kid3 gene. Biochem. Biophys. Acta 1490, 153-158. doi: 10.1016/S0167-4781(99)00239-0

Weber, A., Marquardt, J., Elzi, D., Forster, N., Starke, S., Glaum, A., et al. (2008). Zbtb4 represses transcription of P21CIP1 and controls the cellular response to p53 activation. EMBO J. 27, 1563-1574. doi: 10.1038/emboj.2008.85

Weng, M.-Z., Zhuang, P.-Y., Hei, Z.-Y., Lin, P.-Y., Chen, Z.-S., Liu, Y.-B., et al. (2014). ZBTB20 is involved in liver regeneration after partial hepatectomy in mouse. Hepatobil. Pancreatic Dis. Int. 13, 48-54. doi: 10.1016/S14993872(14)60006-0

White, R. B., Biérinx, A.-S., Gnocchi, V. F., and Zammit, P. S. (2010). Dynamics of muscle fibre growth during postnatal mouse development. BMC Dev. Biol. 10:21. doi: 10.1186/1471-213X-10-21

Yang, W. S., Chadalapaka, G., Cho, S. G., Lee, S. O., Jin, U. H., Jutooru, I., et al. (2014). The transcriptional repressor ZBTB4 regulates EZH2 through a MicroRNA-ZBTB4-specificity protein signaling axis. Neoplasia 16, 1059-1069. doi: 10.1016/j.neo.2014.09.011

Yoshida, N., Yoshida, S., Koishi, K., Masuda, K., and Nabeshima, Y.-I. (1998). Cell heterogeneity upon myogenic differentiation: down-regulation of MyoD and Myf-5 generates 'reserve cells'. J. Cell Sci. 111, 769-779.

Zammit, P. S., Golding, J. P., Nagata, Y., Hudon, V., Partridge, T. A., and Beauchamp, J. R. (2004). Muscle satellite cells adopt divergent fates: a mechanism for self-renewal? J. Cell Biol. 166, 347-357. doi: $10.1083 /$ jcb.200312007

Zammit, P. S., Partridge, T. A., and Yablonka-Reuveni, Z. (2006a). The skeletal muscle satellite cell: the stem cell that came in from the cold. J. Histochem. Cytochem. 54, 1177-1191. doi: 10.1369/jhc.6R6995.2006
Zammit, P. S., Relaix, F., Nagata, Y., Pérez-Ruiz, A., Collins, C., Partridge, T., et al. (2006b). Pax7 and myogenic progression in skeletal muscle satellite cells. J. Cell Sci. 119, 1824-1832. doi: $10.1242 /$ jcs. 02908

Zhao, J. G., Ren, K. M., and Tang, J. (2014). Zinc finger protein ZBTB20 promotes cell proliferation in non-small cell lung cancer through repression of FoxO1. FEBS Lett. 588, 4536-4542. doi: 10.1016/j.febslet.2014. 10.005

Zhou, G., Jiang, X., Zhang, H., Lu, Y., Liu, A., Ma, X., et al. (2015). Zbtb20 regulates the terminal differentiation of hypertrophic chondrocytes via repression of Sox9. Development 142, 385-393. doi: 10.1242/dev. 108530

Zhou, X., Benson, K. F., Ashar, H. R., and Chada, K. (1995). Mutation responsible for the mouse pygmy phenotype in the developmentally regulated factor HMGI-C. Nature 376, 771-774. doi: 10.1038/376771a0

Zhou, X., and Chada, K. (1998). HMGI family proteins: architectural transcription factors in mammalian development and cancer. Keio J. Med. 47, 73-77. doi: $10.2302 / \mathrm{kjm} .47 .73$

Conflict of Interest Statement: The authors declare that the research was conducted in the absence of any commercial or financial relationships that could be construed as a potential conflict of interest.

Copyright (c) 2016 Alonso-Martin, Rochat, Mademtzoglou, Morais, de Reyniès, Auradé, Chang, Zammit and Relaix. This is an open-access article distributed under the terms of the Creative Commons Attribution License (CC BY). The use, distribution or reproduction in other forums is permitted, provided the original author(s) or licensor are credited and that the original publication in this journal is cited, in accordance with accepted academic practice. No use, distribution or reproduction is permitted which does not comply with these terms. 